\title{
Impact of Kinetic Uncertainties on Accurate Prediction of NO Concentrations in Premixed Alkane-Air Flames
}

\author{
Antoine Durocher ${ }^{a, *}$, Philippe Versailles ${ }^{a, b}$, Gilles Bourque $^{a, b}$, \\ Jeffrey M. Bergthorson ${ }^{a}$ \\ ${ }^{a}$ Department of Mechanical Engineering, McGill University, Canada \\ ${ }^{b}$ Siemens Canada Limited, Canada
}

\begin{abstract}
Accurate thermochemical mechanisms that can predict the formation of nitrogen oxides $\left(\mathrm{NO}_{x}\right)$ are important design tools for low-emissions engines. The lack of accurate direct measurements of reaction rates, and the associated measurement scatter, have resulted in recommended rate parameters for individual chemical reactions that have large uncertainty intervals. In an effort to quantify the impact of these parametric uncertainties on emissions predictions, forward uncertainty propagation is performed with five spectral methods. Sparse grids are identified as the optimal technique to rapidly construct accurate surrogate models. Subsequent polynomial expansions with sparse grids, performed in one-dimensional atmospheric laminar flames for only the 30 uncertain reactions that greatly affect NO formation, produce uncertainty intervals two orders of magnitude larger than nominal predictions. Primary uncertainty sources were identified with reaction pathway analyses to evaluate the contribution of individual formation routes and the uncertainties in prompt NO were found to propagate mostly from the $\mathrm{CH}$ chemistry. These results highlight the necessity of a comprehensive approach, using experimental measurements with uncertainty quantification and inference techniques, to reduce uncertainty and develop predictive $\mathrm{NO}_{x}$ models.
\end{abstract}

Keywords - Uncertainty quantification, NO modelling, reaction pathway analysis, predictive modelling

Funding: The authors wish to acknowledge the support of the Fonds de Recherche du Québec - Nature et Technologies (FRQNT), the Natural Sciences and Engineering Research Council of Canada (NSERC), and Siemens Canada Limited.

${ }^{*}$ Corresponding author: antoine.durocher@mail.mcgill.ca 


\section{Nomenclature}

\begin{tabular}{|c|c|}
\hline$I$ & Integration operator \\
\hline$K$ & Number of terms in the expansion \\
\hline $\mathrm{MC}$ & Monte Carlo \\
\hline$P_{i}$ & Orthogonal polynomial basis of order $i$ \\
\hline PCE & Polynomial chaos expansion \\
\hline $\mathrm{PDF}$ & Probability density function \\
\hline$Q$ & Quadrature operator \\
\hline$R$ & Response, quantity of interest \\
\hline RPA & Reaction pathway analysis \\
\hline$S_{\mathrm{u}}$ & Reference flame speed \\
\hline$T$ & Temperature \\
\hline$X_{i}$ & Mole fraction of species $i$ \\
\hline$f$ & Reaction rate uncertainty factor \\
\hline$[i]$ & Concentration of species $i$ \\
\hline$k$ & Specific reaction rate constant \\
\hline$\ell$ & Level of accuracy of the quadrature rule \\
\hline$n$ & Number of variables in the expansion \\
\hline$p$ & Order of the polynomial expansion \\
\hline$w^{r}$ & Weight of the quadrature point $r$ \\
\hline $\mathbf{x}$ and $x_{i}$ & Variable studied in the spectral expansion; vector and scalar elements \\
\hline$\alpha$ & Coefficients of the polynomial expansion \\
\hline$\Delta_{\ell}$ & Nested quadrature operator at level $\ell$ \\
\hline$\mu$ & $1^{\text {st }}$ moment, average \\
\hline$\rho_{x}$ & Joint probability density function \\
\hline$\sigma$ & $2^{\text {nd }}$ moment, standard deviation \\
\hline$\tau$ & Residence time \\
\hline$\phi$ & Equivalence ratio \\
\hline$\psi$ & One-dimensional polynomial basis \\
\hline$\Psi$ & Multivariate polynomial combinations \\
\hline & Subscripts \\
\hline low & Lower uncertainty limit \\
\hline high & Upper uncertainty limit \\
\hline & Superscripts \\
\hline$(1)$ & One-dimensional operator \\
\hline$(2)$ & Two-dimensional operator \\
\hline (n) & N-dimensional operator \\
\hline$r$ & Node of the quadrature rule \\
\hline
\end{tabular}




\section{Introduction}

Chemical kinetic models are known to exhibit large variability in the predictions of nitrogen oxides ( $\mathrm{NO}$ and $\mathrm{NO}_{2}$, or $\mathrm{NO}_{x}$ ) (Watson et al., 2016). The lack of reliable predictive models means that, in the gas turbine industry, $\mathrm{NO}_{x}$ emissions are estimated using empirical correlations developed through expensive test campaigns. Moving towards low- $\mathrm{NO}_{x}$ technology, detailed and accurate understanding of the chemistry is necessary to reduce risks, costs, and development time of new designs that can satisfy increasingly stringent regulations (Lieuwen et al., 2013).

$\mathrm{NO}_{x}$ submodels generally include the four production routes identified for gaseous hydrocarbon combustion: prompt (Fenimore), thermal (Zel" dovich), $\mathrm{N}_{2} \mathrm{O}$, and NNH (Miller and Bowman, 1989; Glarborg et al., 2018). These models have enabled the development of lowemissions combustors by identifying configurations where emissions could be minimized. For instance, reductions of thermal $\mathrm{NO}_{x}$ in high-temperature, post-flame, zones were achieved in steam-diluted mixtures and lean conditions (Göke et al., 2014; Røkke et al., 2003; Correa, 1993). Yet, the lack of fundamental knowledge on formation pathways, and different choices of optimization targets, led to the development of a wide variety of tailored thermochemical mechanisms that contain unique sets of reactions, species, and kinetic rates (Schofield, 2012). This inherent uncertainty limits the value of such mechanisms as predictive tools for design.

Uncertainty analysis is now recognized as a necessary element in any combustion modelling effort to quantify the impact of model uncertainty (Wang and Sheen, 2015; Prager et al., 2013). Expensive sampling methods, using response surfaces, were historically used to quantify the impact of uncertain kinetic rate parameters on model predictions (Frenklach et al., 1992; Zsély et al., 2008). The introduction of non-intrusive spectral methods, stemming from the work of Wiener (1938), offered an economic strategy to generate accurate response surfaces that could capture non-linear interactions (Reagan et al., 2005). Forward propagation of parametric uncertainties has been used to provide prediction intervals on laminar flame speeds and ignition delay times, before inference was used to constrain the pa- 
rameter space with experimental measurements (Sheen and Wang, 2011; Prager et al., 2013). Mechanism optimizations were also performed under uncertainty with large datasets using PrIMe to constrain a model for syngas combustion (Slavinskaya et al., 2017). Few studies, however, have been performed to quantify the effect of parametric uncertainties on $\mathrm{NO}_{x}$ emissions (Tomlin, 2006; Zsély et al., 2008). Employing a stochastic approach, Zsély et al. (2008) quantified the uncertainty inherent to NO production in perfectly stirred reactors, and showed that prediction uncertainties are driven by kinetic rather than thermodynamic parameters. Similar results were found with a linear analysis in exhaust-gas-recirculated opposed-flow flames (Lipardi et al., 2017).

This work first investigates various non-intrusive spectral uncertainty quantification techniques to identify an optimal approach to characterize uncertainties in emissions predictions caused by uncertain kinetic parameters. Total-order expansions, tensor-product expansions, and sparse grids are used to propagate the parametric uncertainties, of the nine most uncertain reactions having the largest impact on $\mathrm{CH}$ formation identified by Versailles et al. $\left(2017^{b}\right)$, through the combustion model to provide probability intervals on $\mathrm{CH}$ concentration. Subsequently, $\ell_{2}$ sparse grids are used to quantify global uncertainties in total [NO] predictions, and evaluate the contributions of the four production routes for lean to rich methane-air flames. Two different $\mathrm{NO}_{x}$ submodels are used to investigate primary sources of uncertainty. The results of this analysis will inform further experiments, as well as model revisions and optimizations.

\section{Methodology}

The introduction of non-intrusive spectral methods has provided an economic alternative to the sampling techniques historically used to develop response surfaces (Frenklach et al., 1992). The algebraic description of complex phenomena enables quick evaluation of the entire parameter space to quantify uncertainties and to optimize reaction rates against experimental data. However, any inaccuracies in the response surfaces will necessarily lead to modelling 
errors. The framework shown in Fig. 1 is used to construct surrogate models for uncertainty quantification. The approach combines direct combustion simulations using Cantera 2.3 (Goodwin et al., 2016) with the uncertainty toolbox from Dakota 6.6 (Adams et al., 2015). The following four main steps are performed:

1. The reactions that greatly affect the quantity of interest and are uncertain are first identified to focus the analysis. Physically realistic uncertainty limits are obtained from the literature to bound the uncertain parameter space. A spectral method is selected, along with the desired polynomial order for the surrogate model, and the location of the collocation points are obtained in the normalized uncertain space.

2. Direct simulations are performed at collocation points representing unique combinations of reaction-rate parameters. The process is repeated with new combinations until the required number of samples is reached. Species concentrations and pathway contributions are extracted from complete solutions to develop the surrogate model.

3. Coefficients of the polynomial expansion are evaluated and the response surface is assembled using the prescribed polynomial bases and polynomial order defined initially.

4. The surrogate model is randomly and heavily sampled over the entire uncertain space to obtain probability distributions, or "error bars", on predictions. These probability distributions represent the effect of the inherent uncertainty of the reaction-rate parameters, selected initially, on the combustion chemistry model studied.

\subsection{Identification of reactions and uncertainty limits}

In order to reduce the dimensions of the problem, and the required number of simulations, the surrogate model development is limited to reactions that have a large impact on predictions within parametric uncertainty limits. The limited set of reactions can be used to quantify the impact of major uncertainty sources (Zádor et al., 2005; Davis et al., 2017). In the current 


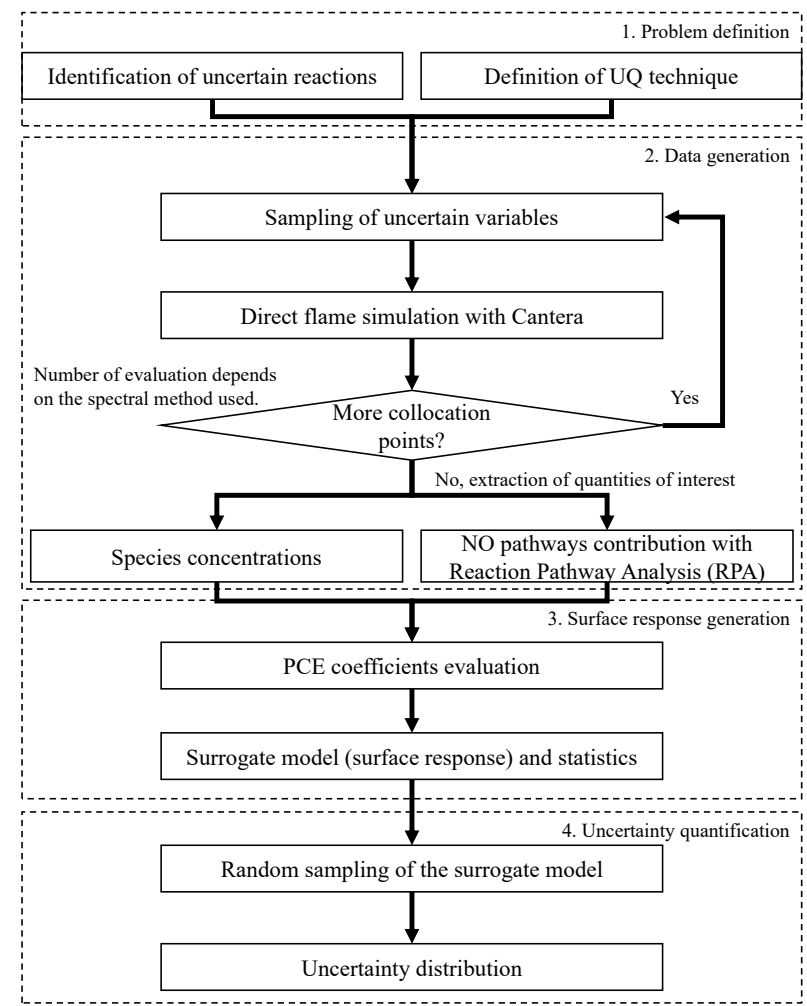

Figure 1: Uncertainty quantification framework using direct flame simulations for surrogate model construction.

work, only kinetic rates are considered in the uncertainty analysis. The uncertainties are provided on the nominal specific reaction rate constant as a multiplier, which is consistent with the format used in the literature (Baulch et al., 1992; Baulch, 2005; Tsang and Hampson, 1986).

Logarithmic sensitivities, or normalized sensitivities (Turányi and Tomlin, 2016), are first obtained for a range of equivalence ratios from lean to rich conditions to describe a relative change in concentration with respect to a relative change in reaction rate. The sensitivities are then multiplied by the corresponding uncertainty factors, $f$, to obtain uncertaintyweighted sensitivity indices, as shown in Appendix A. Reactions presenting the highest indices are selected to perform the uncertainty analysis.

Probable and physically realistic uncertainty intervals, found in the literature (Baulch et al., 1992; Baulch, 2005; Tsang and Hampson, 1986), bound the kinetic parameter space. 
The reaction rate uncertainty is typically provided in terms of $\Delta \log _{10} k_{i}$ for the $i^{\text {th }}$ reaction. Alternatively, uncertainty factors $f_{i}=10^{\Delta \log _{10} k_{i}}$ can be obtained to multiply nominal specific reaction rates. It is expected that the use of more recent preferred uncertainty limits, or results from inference processes, would further affect the predicted interval, but this work does not aim to provide a review of the most recent measurements. Nominal reaction rates in a given mechanism, $k_{i}$, are obtained from optimization studies using a specific sets of experimental targets, and generally differ from the preferred rates found in the literature. To ensure that the rates are varying within the recommended uncertainty interval, relative errors should be expressed for the lower and upper uncertainty limits separately, as follows:

$$
\begin{aligned}
\left.\frac{\Delta k_{i}}{k_{i}}\right|_{\text {low }} & =\frac{k_{i} / f_{i}-k_{i}}{k_{i}}=\frac{1}{f_{i, \text { low }}}-1 \\
\left.\frac{\Delta k_{i}}{k_{i}}\right|_{\text {high }}= & =\frac{k_{i} \cdot f_{i}-k_{i}}{k_{i}}=f_{i, \text { high }}-1
\end{aligned}
$$

The resulting asymmetric bands, shown in Fig. 2, retain the unique mechanism structure and cover the entire recommended uncertainty space.

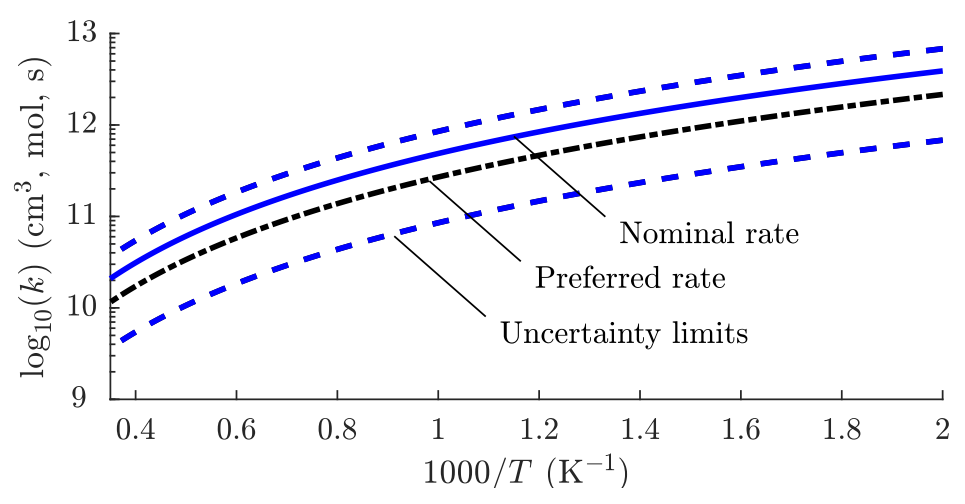

Figure 2: Specific reaction rate constant $k$ for the reaction $\mathrm{H}+\mathrm{OH}+\mathrm{M} \rightleftharpoons \mathrm{H}_{2} \mathrm{O}+\mathrm{M}$ for $\mathrm{M}=\mathrm{N}_{2}$. Legend: - - Baulch (2005) with preferred uncertainty limits ---, —SD with corresponding common uncertainty limits ---. 


\subsection{Uncertainty quantification techniques}

Uncertainties in combustion systems were traditionally quantified by stochastic methods (Tomlin, 2006; Zsély et al., 2008), and have recently been studied with spectral methods, or polynomial chaos expansions (PCE) (Sheen and Wang, 2011; Wang and Sheen, 2015). The introduction of such methods by Wiener (1938) provided an economic alternative to construct surrogate models that can be used in sensitivity analyses, model optimization, and uncertainty quantification. However, the number of collocation points grows exponentially with the dimensions of the problem. The curse of dimensionality implies that an accurate description of high-dimensional problems can become computationally expensive. The current work first examines various techniques for optimal methods requiring the least number of evaluations for accurate and robust quantification of uncertainties in predictions of pollutant species. A Monte Carlo (MC) simulation first provides the reference distributions for the quantities of interest. The traditional $1^{\text {st }}$ - and $2^{\text {nd }}$-order polynomial expansions are then compared to the distributions, followed by the tensor-product and sparse-grid formulations.

No significant statistics can be derived, due to scarce experimental measurements, for the prior distribution of the kinetic rates within their uncertainty bands, so uniform distributions are assumed to avoid bias. Additional measurements would be required to identify prior probability distributions. Consequently, Legendre polynomials are used with normalized limits, between $[-1,1]$ (Askey and Wilson, 1985). The choice of uniform distributions is expected to not significantly affect the predicted uncertainty, compared to normal distributions. The sum of $N$ uniformly-distributed variables approaches a normal distribution under the Central Limit Theorem, and the number of variables studied in the current work should be large enough. This demonstration has been performed in ethylene-air mixtures, where the two resulting distributions show similar widths (Sheen and Wang, 2011).

MC and advanced sampling techniques, such as Latin hypercube sampling (LHS) shown in Fig. 3a, provide an intuitive way to assess numerical uncertainties. With enough randomly selected samples, the solution should approach the true distribution based on the law of large 

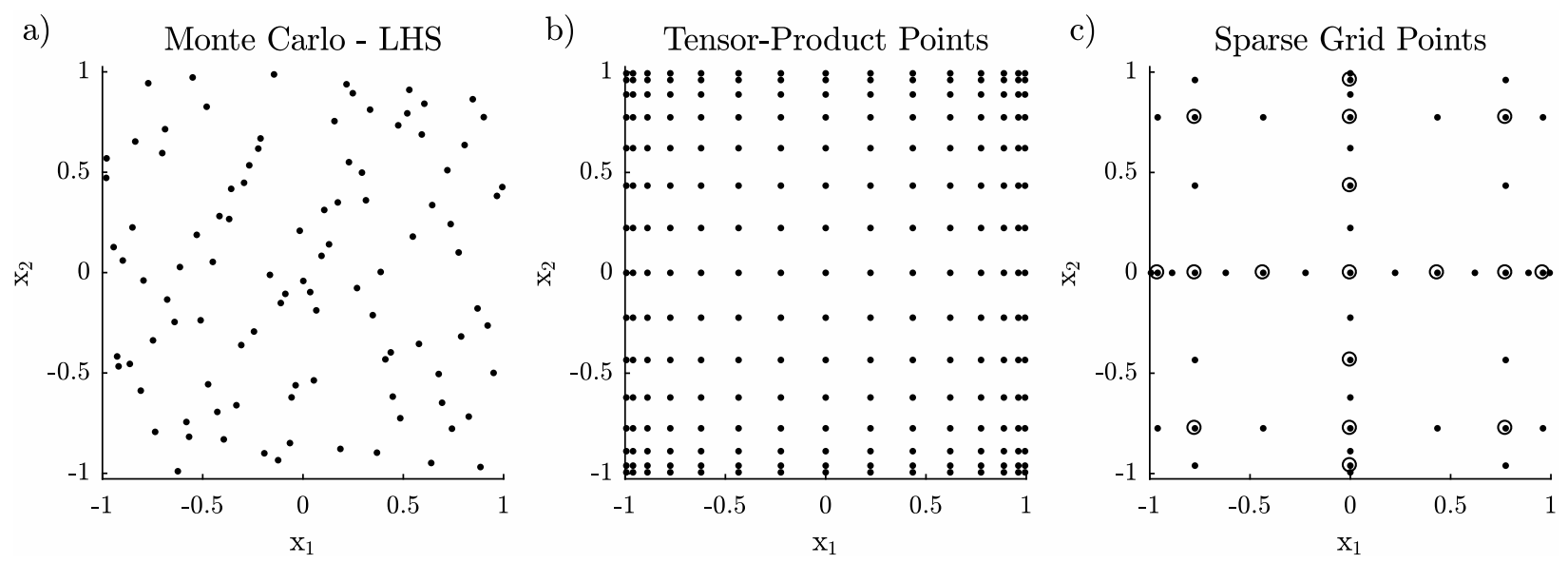

Figure 3: Collocation points examples to evaluate the coefficients of a spectral expansion for two variables $x_{1}$ and $x_{2}$ : a) Monte Carlo with (LHS), b) Tensor-product, and c) sparse grid points with a nested Gauss-Patterson quadrature rule where the accuracy per-dimension basis is maintained. $\ell_{2}$ and $\ell_{3}$ sparse grid points are identified by $\circ$ and $\bullet$, respectively.

numbers. Stochastic methods typically require minimal changes to existing tools. They have the advantage of being independent of the dimension of the problem, since the entire space is sampled simultaneously. However, they exhibit slow convergence, even with advanced sampling techniques, which corresponds to high computational costs. More importantly, they do not provide the relationship between the input and output parameters, such that only moments of the statistical distributions (mean, standard deviation, etc.) are obtained.

Spectral methods have been shown to reduce the sample size while retaining the relationship between input and output parameters. The techniques studied in this work are summarized here and greater details can be found in Xiu (2010) and Smith (2013). Similar to Fourier series, polynomial chaos expansions (PCE) suggest that any response $R$ can be expressed by an infinite polynomial expansion:

$$
\begin{aligned}
R(\mathbf{x})=R_{0}+\sum_{k_{1}=1}^{\infty} \alpha_{k_{1}} P_{1}\left(x_{k_{1}}\right) & +\sum_{k_{1}=1}^{\infty} \sum_{k_{2}=1}^{\infty} \alpha_{k_{1}, k_{2}} P_{2}\left(x_{k_{1}}, x_{k_{2}}\right) \\
& +\sum_{k_{1}=1}^{\infty} \sum_{k_{2}=1}^{\infty} \sum_{k_{3}=1}^{\infty} \alpha_{k_{1}, k_{2}, k_{3}} P_{3}\left(x_{k_{1}}, x_{k_{2}}, x_{k_{3}}\right)+\ldots
\end{aligned}
$$


where $\mathbf{x}$ is a vector containing the inputs, or parameters, $x, \alpha_{k_{i}}$ are real coefficients of the expansion for the polynomials $P_{j}\left(x_{k_{1}}, \ldots, x_{k_{j}}\right)$ of order $j$. The expansion can be written in the compact form:

$$
R(\mathbf{x})=\sum_{k=0}^{\infty} \alpha_{k} \Psi_{k}(\mathbf{x})=\sum_{k=0}^{\infty} \alpha_{k} \prod_{i=1}^{n} \psi_{t_{i}^{k}}\left(x_{i}\right),
$$

for a series of $k$ terms describing the relationship between the $n$ variables studied and the response $R$. There is a one-to-one correspondence between the coefficients $\alpha_{k}$ and the polynomials $P_{j}\left(x_{k_{1}}, \ldots, x_{k_{j}}\right)$ and $\Psi_{k}$. The multivariate polynomials $\Psi_{k}(\mathbf{x})$ can also be expressed using the one-dimensional polynomial bases $\psi_{t_{i}^{k}}$ for the $i^{\text {th }}$ variable, where the multi-index $t_{i}^{k}$ describes the polynomial order of the $k^{\text {th }}$ term for the variable $i$. In practise, the series is truncated to a specified polynomial order $p$, approximating a multivariate phenomenon with:

$$
R(\mathbf{x}) \approx \sum_{k=0}^{K} \alpha_{k} \Psi_{k}(\mathbf{x})
$$

where the expansion is limited to $K+1$ terms, which depends on the spectral technique used. With prescribed prior distributions, the polynomial bases $\psi_{i}$ and, therefore, $\Psi_{k}$ are known. Polynomial coefficients can then be evaluated using regression, or spectral projection against each orthogonal polynomial basis function:

$$
\alpha_{k}=\frac{\left\langle R, \Psi_{k}\right\rangle}{\left\langle\Psi_{k}, \Psi_{k}\right\rangle}=\frac{1}{\left\langle\Psi_{k}^{2}\right\rangle} \int_{\Gamma} R(\mathbf{x}) \Psi_{k}(\mathbf{x}) \rho_{\mathbf{x}}(\mathbf{x}) d \mathbf{x}
$$

over the multi-dimensional uncertain domain $\Gamma$, where complete solutions from direct simulations are used to extract $R$, and $\rho_{\mathbf{x}}$ is the joint probability density function evaluated using the prior uniform distributions.

Traditionally, MC integration has been used in total-order expansions to evaluate the integral. The total-order expansion bounds the maximum order of the response surface with the prescribed polynomial order $p$, and the total number of terms $K$ required in Eq. 5 is:

$$
K=\frac{(n+p) !}{n ! p !}
$$


Alternatively, structured grids (Fig. 3b and c), using deterministic quadrature methods, can be used to evaluate the integral in Eq. 6. The one-dimensional quadrature operator approximates the integral with:

$$
I^{(1)} f=\int_{\Gamma_{1}} f(\mathbf{x}) d \mathbf{x} \approx \sum_{r=1}^{m} f\left(\mathbf{x}^{r}\right) w^{r}=Q^{(1)} f
$$

where $f(\mathbf{x})=R(\mathbf{x}) \Psi_{k}(\mathbf{x}) \rho_{\mathbf{x}}(\mathbf{x})$ to simplify notation, and the $m$ nodes, $x^{r}$, and $m$ weights, $w^{r}$, are known for specific quadrature rules. The one-dimensional operator is generalized to $n$-dimensions, or variables, by:

$$
\begin{aligned}
Q_{\ell}^{(n)} f(\mathbf{x}) & =\left(Q_{\ell_{1}}^{(1)} \otimes \ldots \otimes Q_{\ell_{n}}^{(1)}\right) f(\mathbf{x}) \\
& =\sum_{j_{1}=1}^{m_{\ell_{1}}} \ldots \sum_{j_{n}=1}^{m_{\ell_{n}}} f\left(x_{j_{1}}^{\ell_{1}} \ldots x_{j_{n}}^{\ell_{n}}\right)\left(w_{j_{1}}^{\ell_{1}} \otimes \ldots \otimes w_{j_{n}}^{\ell_{n}}\right),
\end{aligned}
$$

along the $\ell^{\text {th }}$-level of integration to yield the tensor-product rule used in tensor-product expansions to evaluate the integral of Eq. 6. It is possible to formulate a nested rule that facilitates quadrature refinement by reusing points from the previous level, $\ell-1$, with the onedimensional quadrature operator $\Delta_{\ell}^{(1)}$ expressing the difference between two nested levels:

$$
\Delta_{\ell}^{(1)} f(\mathbf{x})=\left(Q_{\ell}^{(1)}-Q_{\ell-1}^{(1)}\right) f(\mathbf{x})
$$

as

$$
Q_{\ell}^{(n)} f(\mathbf{x})=\sum_{\max \ell^{\prime} \leq \ell}\left(\Delta_{\ell_{1}}^{(1)} \otimes \ldots \otimes \Delta_{\ell_{n}}^{(1)}\right) f(\mathbf{x}),
$$

where $\ell^{\prime}=\left(\ell_{1}, \ldots, \ell_{n}\right)$ is a multi-index containing the levels of accuracy $\ell_{i}$ for the corresponding variable $i$. In tensor-product expansions, contrary to total-order expansions, the polynomial order bound is applied on a per-dimension basis, creating a response surface with a total polynomial order $p \times n$, assuming isotropic grids. The resulting combinations 
of one-dimensional polynomial bases grow exponentially with the number of variables:

$$
K=\prod_{i=1}^{n}\left(p_{i}+1\right)
$$

where the $n$ and $p_{i}$ represent the number of uncertain variables studied and the polynomial order of the $i^{\text {th }}$ variable, respectively. Assuming isotropy in the polynomial orders, $p_{i}$ takes the prescribed value $p$ for all variables. Tensor-product expansions are, therefore, generally limited to small and medium-sized problems.

Sparse grids were proposed by Smolyak (1963) for use in high-dimensional problems to provide similar accuracy as full tensor-product expansions, while requiring significantly fewer quadrature points. By removing multivariate high-order terms, only a subset of the full tensor-product expansion is retained. Figure 3c illustrates the sparsity of the approach in two dimensions by comparison to the full tensor-product expansion presented in Fig. 3b. The quadrature rule used for sparse grids at the $\ell^{\text {th }}$ level is defined by

$$
Q_{\ell}^{(n)} f(\mathbf{x})=\sum_{\left|\ell^{\prime}\right| \leq \ell+n-2}\left(\Delta_{\ell_{1}}^{(1)} \otimes \ldots \otimes \Delta_{\ell_{n}}^{(1)}\right) f(\mathbf{x})
$$

where $\left|\ell^{\prime}\right|$ is the summation of the level per dimension. The sparse grid formulation only differs from the full tensor-product quadrature rule in Eq. 11 by the definition of the summation limit, removing high-order multivariate polynomials from the expansion. The resolution on a per-dimension basis is conserved, and lower-order cross-correlation effects between parameters are still captured. The nested nature of the formulation can be observed in Fig. 3c for $\ell_{2}$ and $\ell_{3}$ sparse grids where the additional level of refinement adds point to the previous formulation. Additionally, both tensor-product formulations and sparse grids support anisotropic development to favour high-order polynomials only for sensitive parameters, as performed in sparse pseudo-spectral methods by Winokur et al. (2016). No unique formula defines the number of points required to determine the response surface, as it is dependent on the quadrature formulation used and the polynomial orders per variables. 


\section{Spectral method comparison}

An extensive series of $[\mathrm{NO}],[\mathrm{CH}]$, temperature, and velocity measurements in atmosphericpressure stagnation flames, for lean to rich $\mathrm{C}_{1}-\mathrm{C}_{4}$ alkane and alcohol fuels has recently been published (Watson et al., 2016, 2017; Versailles et al., 2016). A comparison of predictions from a selection of mechanisms to the quantitative absolute measurements obtained with Laser-Induced Fluorescence (LIF) showed significant discrepancy between various models and experiments. Versailles et al. $\left(2017^{b}\right)$ subsequently reconciled predictions with $\mathrm{CH}-$ LIF measurements through the optimization of only nine reactions shown in Tab. 1. These reactions were identified by the uncertainty-weighted sensitivity analysis performed for $\mathrm{C}_{1}-\mathrm{C}_{3}$ alkane-air mixtures with equivalence ratios ranging from 0.7 to 1.3 . Only the uncertainties in these nine chemical kinetic rates are propagated through atmospheric-pressure stagnationflame simulations using the base chemistry from the San Diego (SD) mechanism (University of California at San Diego, 2005). The impacts on peak methylidyne concentrations, $[\mathrm{CH}]_{\text {peak }}$, $\mathrm{NO}_{x}$ concentrations $10 \mathrm{~ms}$ downstream the flame front, and reference flame speed, $S_{\mathrm{u}}$, are first quantified to assess the accuracy of five different spectral methods.

$\mathrm{CH}$ and velocity profiles obtained through stochastic sampling of the uncertain kinetic

Table 1: Uncertainty limits, $1 / f_{i, \text { low }}$ and $f_{i \text {, high }}$.

\begin{tabular}{rlcl}
\hline \hline \multicolumn{2}{c}{ Reactions } & $1 / f_{i, \text { low }}$ & $f_{i, \text { high }}$ \\
\hline $\mathrm{CH}+\mathrm{O}_{2}$ & $\rightleftharpoons \mathrm{HCO}+\mathrm{O}$ & 0.4747 & 2.456 \\
$\mathrm{CH}_{2}+\mathrm{OH}$ & $\rightleftharpoons \mathrm{CH}+\mathrm{H}_{2} \mathrm{O}$ & 0.2409 & 2.168 \\
$\mathrm{CH}_{2}+\mathrm{H}$ & $\rightleftharpoons \mathrm{CH}+\mathrm{H}_{2}$ & 0.7579 & 127.6 \\
$\mathrm{H}+\mathrm{CH}_{3}(+\mathrm{M})$ & $\rightleftharpoons \mathrm{CH}_{4}(+\mathrm{M})$ & 0.2577 & 3.246 \\
$\mathrm{CH}_{3}+\mathrm{OH}$ & $\rightleftharpoons \mathrm{CH}_{2}^{*}+\mathrm{H}_{2} \mathrm{O}$ & 0.3653 & 2.324 \\
$\mathrm{CH}+\mathrm{H}_{2} \mathrm{O}$ & $\rightleftharpoons \mathrm{CH}_{2} \mathrm{O}+\mathrm{H}$ & $3.823 \cdot 10^{-2}$ & 5.295 \\
$\mathrm{CH}_{2}+\mathrm{O}_{2}$ & $\rightleftharpoons \mathrm{CO}+\mathrm{OH}+\mathrm{H}$ & 0.8482 & 8.482 \\
& $\rightleftharpoons \mathrm{CO}_{2}+\mathrm{H}_{2}$ & & \\
$\mathrm{CH}_{2} \mathrm{CO}+\mathrm{O}$ & $\rightleftharpoons \mathrm{CH}_{2}+\mathrm{CO}_{2}$ & $5.808 \cdot 10^{-3}$ & 1.502 \\
\hline \hline
\end{tabular}



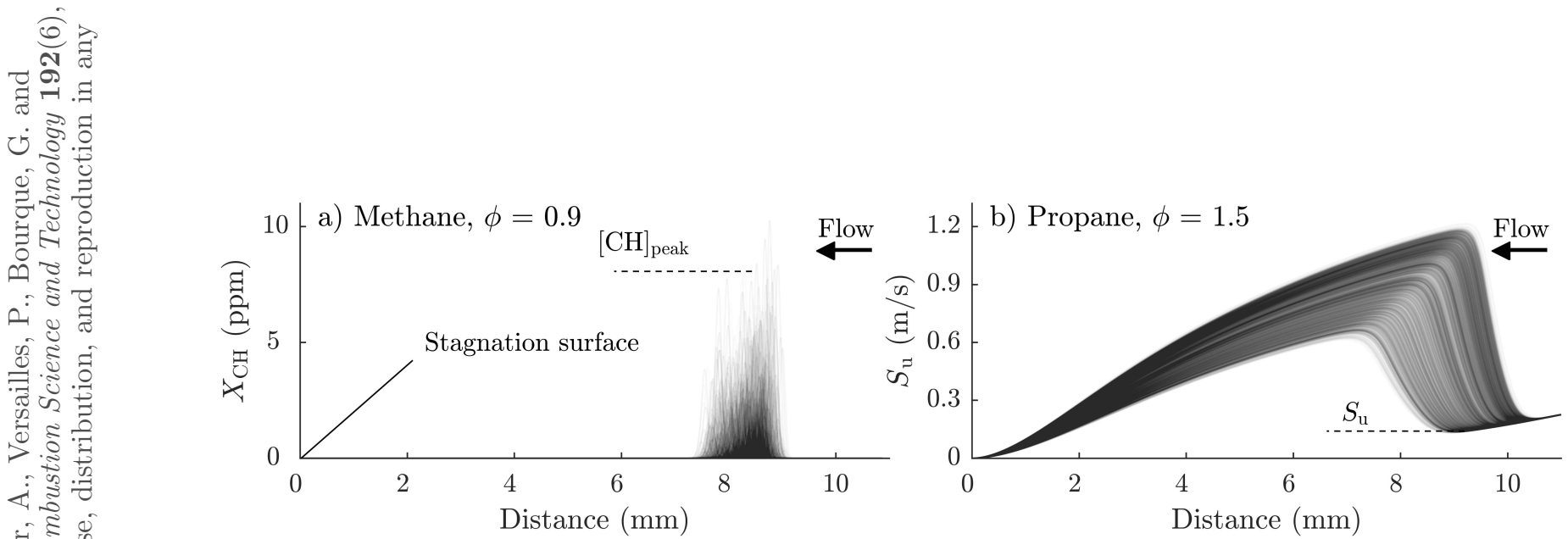

Figure 4: $\mathrm{CH}$ and velocity profiles for realizations of the kinetic parameter uncertainty space in atmospheric-pressure stagnation flames. A significant profile variability is observed as the reactivity changes, which affects both the flame speed and its position in a stagnation flow.

parameter space are shown in Fig. 4 for stagnation flames of lean methane-air and rich propane-air mixtures. A significant variability is observed in profiles since the reaction rates differ from one evaluation to the other, which affect the reactivity of the flame and its position in a stagnation flow. $[\mathrm{CH}]_{\text {peak }}$ is identified as the maximum $\mathrm{CH}$ concentration along its profile from a single simulation. Similarly, the reference flame speed, $S_{\mathrm{u}}$, is obtained from each simulation at the local minimum after the inlet nozzle before the flow accelerates through the flame.

Reference uncertainty distributions are extracted from Monte Carlo simulations with 4,000 samples to assess the accuracy of various spectral methods. The surrogate models developed with various spectral methods are combinations of univariate Legendre polynomials based on the uniform prior distributions (Askey and Wilson, 1985). They are then sampled 100,000 times to quantify uncertainties in predictions. Total-order expansions are performed with (1) $1^{\text {st }}$-order expansions and (2) $2^{\text {nd }}$-order expansions using the minimum number of collocation points $K$ from Eq. 7, and (3) $2^{\text {nd }}$-order expansions with $4 K$ points. Expansions with quadrature methods are completed with (4) $2^{\text {nd }}$-order tensor-product expansions and (5) level $2, \ell_{2}$, sparse grids using a nested Gauss-Patterson formulation. The response surfaces developed with sparse grids yield polynomials reaching a $5^{\text {th }}$-order approximation per dimension and exhibit pairwise variable interactions up to fourth-order polynomials. 
The surrogate models for the $\mathrm{CH}$ radical are developed for the logarithm of concentration, but the figures presented in the current work are in absolute concentration values. This approach provides better characterisation of the response surfaces at concentration close to zero, and prevents extrapolation errors to non-physical, negative, values by allowing strictly positive concentration predictions. The uncertainty analysis is therefore performed for $\log _{10}\left([\mathrm{CH}]_{\text {peak }}\right)$ and the results are transformed back to present ppm values.

\subsection{Method Accuracy}

The first two moments of the distributions: the mean, $\mu$, and the standard deviation, $\sigma$, are shown in Tab. 2 for the five techniques. A selection of lean to rich mixtures of varying fuel compositions are selected to demonstrate the accuracy of the approaches. A lean methaneair mixture, $\phi=0.9$, a stoichiometric ethane-air mixture, and a rich propane-air mixture, $\phi=1.5$, are selected to assess the accuracy of the $[\mathrm{CH}]_{\text {peak }},\left[\mathrm{NO}_{x}\right]$, and $S_{\mathrm{u}}$ expansions, respectively. Each method is shown to produce reasonable statistical estimates of the first moment, even the simplest $1^{\text {st }}$-order approximation with only nine collocation points. Larger discrepancies are observed in the second moments, but every method is still capturing the same order of magnitude in the standard deviation. For $\mathrm{CH}$ concentrations, all the methods demonstrate similar accuracy on the first two moments.

The reference MC distributions for the same operating conditions, shown as histograms in Fig. 5, are subsequently used to assess the capability of the five spectral methods to accurately capture complex distribution shapes. To facilitate comparison, the PCE solutions are shown by solid lines and should envelop the reference MC distributions. First, as suspected by the statistical moments, the five techniques investigated accurately capture $[\mathrm{CH}]_{\text {peak }}$ in Fig. 5a. The most probable concentration and the rapidly increasing probability distribution near zero are both well captured by every approach. Using logarithm values result in accurate quantification as the radical concentrations change rapidly over multiple orders of magnitude. This indicates that low-order methods could be used with confidence to construct surrogate 
models, to perform optimization and inference processes of radical species, when the target is transformed to logarithmic space.

The other two targets investigated here, however, do require higher-order methods to accurately quantify uncertainties in predictions. Total-order expansion techniques with $1^{\text {st }}$ and $2^{\text {nd }}$-order polynomials do not capture the sharp distribution peaks in $\left[\mathrm{NO}_{x}\right]$ and $S_{\mathrm{u}}$. Significantly wider distributions are also observed, with the tails extending to lower concentration values, caused by approximation errors in the surrogate model near the edges of the parameter space. The addition of randomly placed collocation points in the $2^{\text {nd }}$-order totalorder expansion, from $K$ to $4 K$ points, is shown to reduce this error by allowing a better mapping of the uncertainty space as more points are used to perform the spectral projection, or regression, to evaluate the coefficients of the expansion. The increased number of points does not change the polynomial order of the surrogate model, which cannot capture the complexities of the multi-dimensional non-linear problem. Consequently, wide distribution tails are still observed, but the increased number of points allows a better mapping of the uncertain space and reduces the extrapolation error when the regression is performed to construct response surfaces.

Quadrature techniques answer the shortcomings of total-order expansions by accurately

Table 2: Average and standard deviation comparison of uncertainty quantification techniques in $[\mathrm{CH}]_{\text {peak }}$ for a methane-air mixture, $\phi=0.9,\left[\mathrm{NO}_{x}\right]$ for a stoichiometric ethane-air mixture, and $S_{\mathrm{u}}$ for a rich propane-air mixture, $\phi=1.5$.

\begin{tabular}{ccccccc}
\hline \hline Method (Points) & {$[\mathrm{CH}]_{\text {peak }}(\mathrm{ppm})$} & \multicolumn{2}{c}{$\left[\mathrm{NO}_{x}\right](\mathrm{ppm})$} & \multicolumn{2}{c}{$S_{\mathrm{u}}(\mathrm{m} / \mathrm{s})$} \\
& $\mu$ & $\sigma$ & $\mu$ & $\sigma$ & $\mu$ & $\sigma$ \\
\hline Monte Carlo (4,000) & 1.563 & 1.494 & 43.24 & 10.49 & 0.1733 & 0.02088 \\
$1^{\text {st }}$-order total-order (9) & 1.539 & 1.144 & 44.22 & 11.54 & 0.1746 & 0.01996 \\
$2^{\text {nd }}$-order total-order (45) & 1.568 & 2.000 & 43.55 & 11.67 & 0.1740 & 0.02661 \\
$2^{\text {nd }}$-order total-order (180) & 1.543 & 1.438 & 43.72 & 11.06 & 0.1472 & 0.02397 \\
$2^{\text {nd }}$-order tensor-product (6,561) & 1.548 & 1.394 & 43.70 & 10.62 & 0.1740 & 0.02073 \\
$\ell_{2}$ sparse grid (161) & 1.539 & 1.382 & 43.81 & 10.71 & 0.1751 & 0.02130 \\
\hline \hline
\end{tabular}



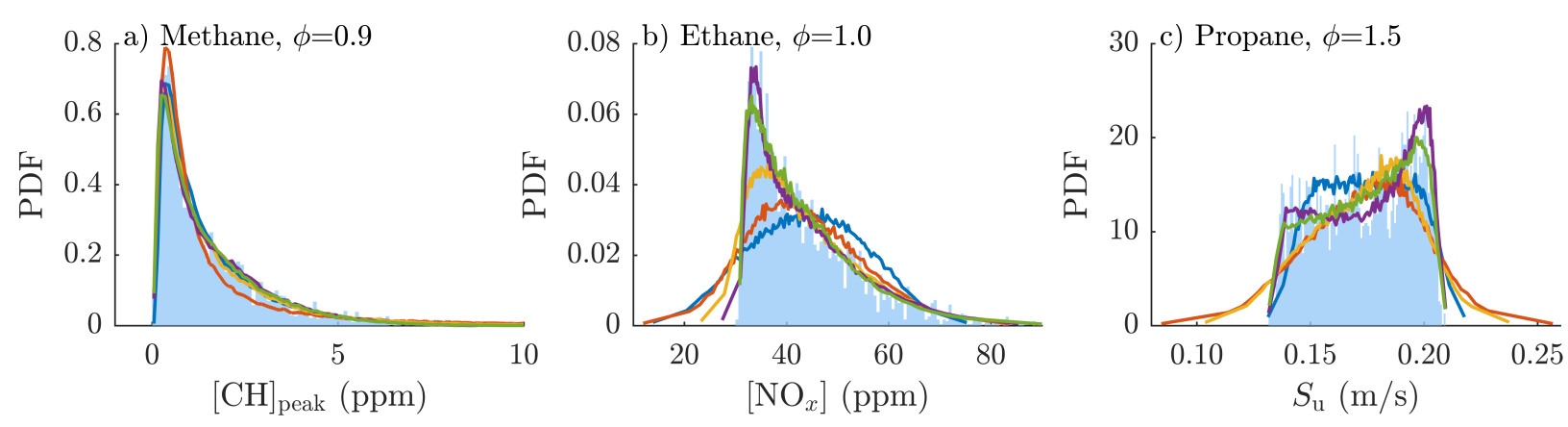

Figure 5: Spectral method comparison to Monte Carlo simulations. : : Monte Carlo distribution (4,000 samples). Total-order expansion, - $: 1^{\text {st }}$-order (9 points), —: $2^{\text {nd }}$-order $(45$ points), - : $2^{\text {nd }}$-order (180 points). Quadrature techniques, - $: 2^{\text {nd }}$-order tensor-product (6,561 points), — $\ell_{2}$ nested sparse grid using Gauss-Patterson rule (161 points).

capturing the distribution widths and shapes. The $2^{\text {nd }}$-order tensor-product expansion provides high-order multivariate polynomials that capture variable interactions, but represent a significant computational cost with 6,561 quadrature points required to build the surrogate model. It demonstrates the limitations of full tensor-product expansion for medium-sized problems and its prohibitive computational cost in large multivariate phenomena. Sparse grids, however, do capture the shapes with similar accuracy, yet they require only 161 quadrature points. The high-order approximation per dimension, provided by the $\ell_{2}$ formulation, are sufficient to construct an accurate surrogate model at low costs. Finally, comparing the sparse grid approach, with 161 points, to the $2^{\text {nd }}$-order total-order expansion, with 181 points, the former exhibits a greater accuracy for a similar computational cost.

As a result, sparse grids are considered the optimal approach to accurately quantify uncertainties in emissions predictions and other targets resulting from complex multi-physics combustion phenomena. For fast-radical species, such as $\mathrm{CH}$, however, low-order methods are found to be sufficient to accurately capture the uncertainty distributions when the surrogate model is constructed using the logarithm of concentrations. For rapid assessment of means and standard deviations, on a day-to-day basis, $1^{\text {st }}$-order total-order expansions are recommended with every combustion modelling attempt to, at least, provide uncertainty 
estimates along with nominal predictions.

\subsection{Numerical uncertainties on $\mathrm{CH}$ predictions}

Figure 6 quantify prediction uncertainties in $[\mathrm{CH}]_{\text {peak }}$ for $\mathrm{C}_{1}-\mathrm{C}_{3}$ alkane-air mixtures in lean to rich conditions against the reference MC distributions. The $\ell_{2}$ sparse grid methodology is selected based on the previous analysis as the current work focuses on quantifying uncertainties in emissions predictions, as well as in $\mathrm{CH}$. Nominal solutions obtained with the commonly used, GRI-Mech 3.0 (GRI) (Smith et al., 1999) and the SD mechanism, are also provided. Additionally, experimental CH-LIF measurements obtained by Versailles et al. (2016) are added to provide a comparison of predictions against state-of-the-art non-intrusive laser measurement techniques. The first three rows present vertical slices of the equivalence ratio sweep shown in the bottom row, where the shading corresponds to the probability distributions, with darker region coinciding with more probable predictions.

The propagation of parametric uncertainties, from only nine reactions in the $\mathrm{CH}$ pathways, yields predictions of $[\mathrm{CH}]_{\text {peak }}$ that reach up to $\sim 400 \%$, at the upper $2 \sigma$ uncertainty limit compared to the nominal predictions. Current CH-LIF experimental measurements exhibit uncertainties of approximately $\pm 20-40 \%$ for the same operating conditions, shown as red bands in the first three rows, and error bars in the last row, of Fig. 6. The difference in scales between experimental uncertainties and the propagated parametric uncertainties highlights the necessity of a comprehensive approach, using experimental measurements with inference techniques, to reconcile numerical predictions with measurements.

Nominal predictions of the SD and GRI mechanisms present significant variability but, given the large width of the distributions, both can be said to agree within their parametric uncertainties, both with one another and with experimental measurements. The nominal SD solution is found to be closer to the most probable interval and it also better captures the experimental measurements in Fig. 6. Validation is required to extend these conclusions to other conditions, but it is expected that predictions from these mechanisms will agree within 

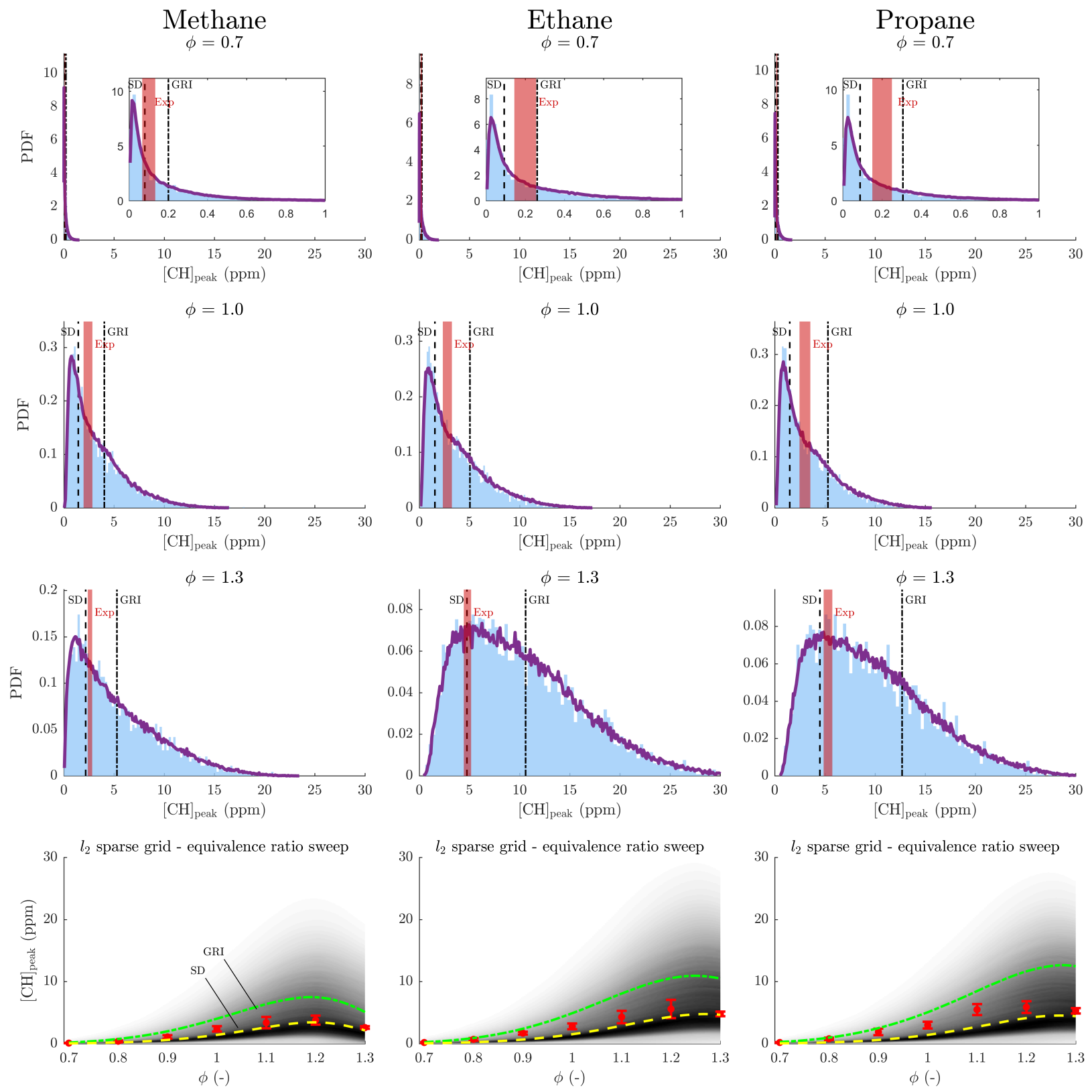

Figure 6: $[\mathrm{CH}]_{\text {peak }}$ distributions for $\mathrm{C}_{1}-\mathrm{C}_{3}$ alkane-air mixtures compared to reference $\square \mathrm{MC}$ simulations (4,000 samples). Spectral results with $\ell_{2}$ nested sparse grid PCE (161 points) are shown by - Vertical lines are nominal mechanism responses for $\operatorname{SD}(---)$ and GRI (-.-). The red bands, corresponding to the measurements and their uncertainty bands, (I) and symbols are experimentally obtained by Versailles et al. $\left(2017^{b}\right)$. 
their uncertainty limits. The current high parametric uncertainty prevents any predictive modelling attempt of $\mathrm{CH}$ concentrations with any confidence.

\section{Uncertainties in nitrogen chemistry}

In hydrocarbon combustion, four NO formation routes are typically found in any modelling attempt: thermal (Zel" dovich), prompt (Fenimore), $\mathrm{N}_{2} \mathrm{O}$, and NNH. Although nitrogen chemistry generally includes a large number of reactions, a limited number control the rate of formation of a given pathway. The thermal NO pathway, active at high temperature, is described by three elementary reactions,

$$
\begin{aligned}
& \mathrm{N}_{2}+\mathrm{O} \rightleftharpoons \mathrm{NO}+\mathrm{N}, \\
& \mathrm{N}+\mathrm{OH} \rightleftharpoons \mathrm{NO}+\mathrm{H}, \text { and } \\
& \mathrm{N}+\mathrm{O}_{2} \rightleftharpoons \mathrm{NO}+\mathrm{O} .
\end{aligned}
$$

The prompt route, active in the flame front, is initiated by the reaction of the $\mathrm{CH}$ radical with molecular nitrogen.

$$
\mathrm{CH}+\mathrm{N}_{2} \rightleftharpoons \mathrm{NCN}+\mathrm{H}
$$

Through several intermediate steps, NCN is oxidized to form NO. The spin-conserved R4 (Moskaleva and Lin, 2000) can be found in recent implementations, while old mechanisms commonly use the spin-forbidden initiation reaction:

$$
\mathrm{CH}+\mathrm{N}_{2} \rightleftharpoons \mathrm{HCN}+\mathrm{N}
$$

Also primarily active within the flame, where high concentrations of $\mathrm{H}$ and $\mathrm{O}$ radicals 
are found, the NNH route proceeds through the following main reactions:

$$
\begin{gathered}
\mathrm{N}_{2}+\mathrm{H}(+\mathrm{M}) \rightleftharpoons \mathrm{NNH}(+\mathrm{M}), \\
\mathrm{NNH}+\mathrm{O} \rightleftharpoons \mathrm{NO}+\mathrm{NH} .
\end{gathered}
$$

Finally, the $\mathrm{N}_{2} \mathrm{O}$ route's essential reactions proceed to $\mathrm{NO}$ after the initial termolecular oxidation of molecular nitrogen:

$$
\begin{aligned}
\mathrm{N}_{2}+\mathrm{O}(+\mathrm{M}) & \rightleftharpoons \mathrm{N}_{2} \mathrm{O}(+\mathrm{M}) \\
\mathrm{N}_{2} \mathrm{O}+\mathrm{O} & \rightleftharpoons \mathrm{NO}+\mathrm{NO} \\
\mathrm{N}_{2} \mathrm{O}+\mathrm{H} & \rightleftharpoons \mathrm{NO}+\mathrm{NH}
\end{aligned}
$$

The $\mathrm{N}_{2} \mathrm{O}$ route is typically favoured in lean conditions, and at high pressures, as shown by recent supra atmospheric NO-LIF measurements (Versailles et al., 2018). In that study, decreasing total NO concentrations with pressure were observed in stagnation flames up to 8 atmospheres, with models predicting an increasing contribution of the $\mathrm{N}_{2} \mathrm{O}$ pathway at high pressures.

Understanding the interaction between species and reactions in modern thermochemical mechanisms proves to be challenging as more species and reactions are introduced. Reaction Pathway Analysis (RPA) helps to understand this complexity by providing a visual representation of the chemical pathways. It connects a network of nodes corresponding to species, using arrows that correspond to reactions. A simplified nitrogen chemistry can be visualized in Fig. 7 where the branching occurs at the initiation reactions R1, R4, R6, and R8, corresponding to the thermal, prompt, $\mathrm{NNH}$, and $\mathrm{N}_{2} \mathrm{O}$ routes, respectively. The method used in this work was improved by Versailles et al. $\left(2016 ; 2017^{a}\right)$ from Grcar et al. (2006). A conserved scalar, here the flux of atomic nitrogen (N), is tracked as reactants are being consumed to products. The rate of transfer from species $s_{1}$ to $s_{2}, R\left(\mathrm{~N}, s_{1}, s_{2}\right)$ is 
spatially-integrated with:

$$
R\left(\mathrm{~N}, s_{1}, s_{2}\right)=\int_{x_{\mathrm{i}}}^{x_{\mathrm{f}}} \sum_{l} n_{l}\left(\mathrm{~N}, s_{1}, s_{2}\right) \cdot q_{l}(x) \cdot \pi r^{2} \mathrm{~d} x
$$

where the number of $\mathrm{N}$ atoms, $n_{l}$, is transferred through reaction $l$ from species $s_{1}$ to $s_{2}$, $q_{l}(x)$ is the rate of progress of reaction $l, x$ is the spatial domain, and $r$ is the radius of the cylindrical control volume. The control volume is adjusted with the radius over the domain with inlet and outlet boundaries, $x_{\mathrm{i}}$ and $x_{\mathrm{f}}$, to yield a known inlet flux of $1 \mathrm{kmole} / \mathrm{s}$ of atomic nitrogen. Therefore, $R\left(\mathrm{~N}, s_{1}, s_{2}\right)$ provide fractions of the flux of nitrogen atoms entering the control volume being consumed by each NO-production route. It is then possible to track the consumption of $\mathrm{N}_{2}$ through the various pathways, using the initiation reactions, and identify their relative contribution to emissions, as shown in Fig. 7 for the thermal, $\mathrm{N}_{2} \mathrm{O}, \mathrm{NNH}$, and prompt pathways which contribute to $26 \%, 34 \%, 15 \%$, and $25 \%$, respectively. Contrary to methods where routes are turned on and off (Guo et al., 2005), which can potentially introduce structural errors to the model and inaccuracy in the assessment of the four routes, the present approach conserves all the species and reactions in the analysis, and requires only a single direct simulation.

\subsection{Comparison to Stagnation Flame Experiments}

Two $\mathrm{NO}_{x}$ sub-mechanisms are attached to the base chemistry of the 2016 San Diego mechanism to quantify uncertainties in NO predictions in one-dimensional flame simulations. First, the latest San Diego nitrogen chemistry, 2004-v2, is chosen to assess the accuracy and precision of the complete optimized mechanism. Second, the recent NOMecha 2.0 (Lamoureux et al., 2016), which includes the spin-conserved prompt initiation reaction, has been selected to quantify the contribution of individual formation pathways to total emissions and uncertainties. A selection of 30 reactions are identified in Appendix A with the NOMecha 2.0 chemistry using uncertainty-weighted logarithmic sensitivity analyses for lean to rich 


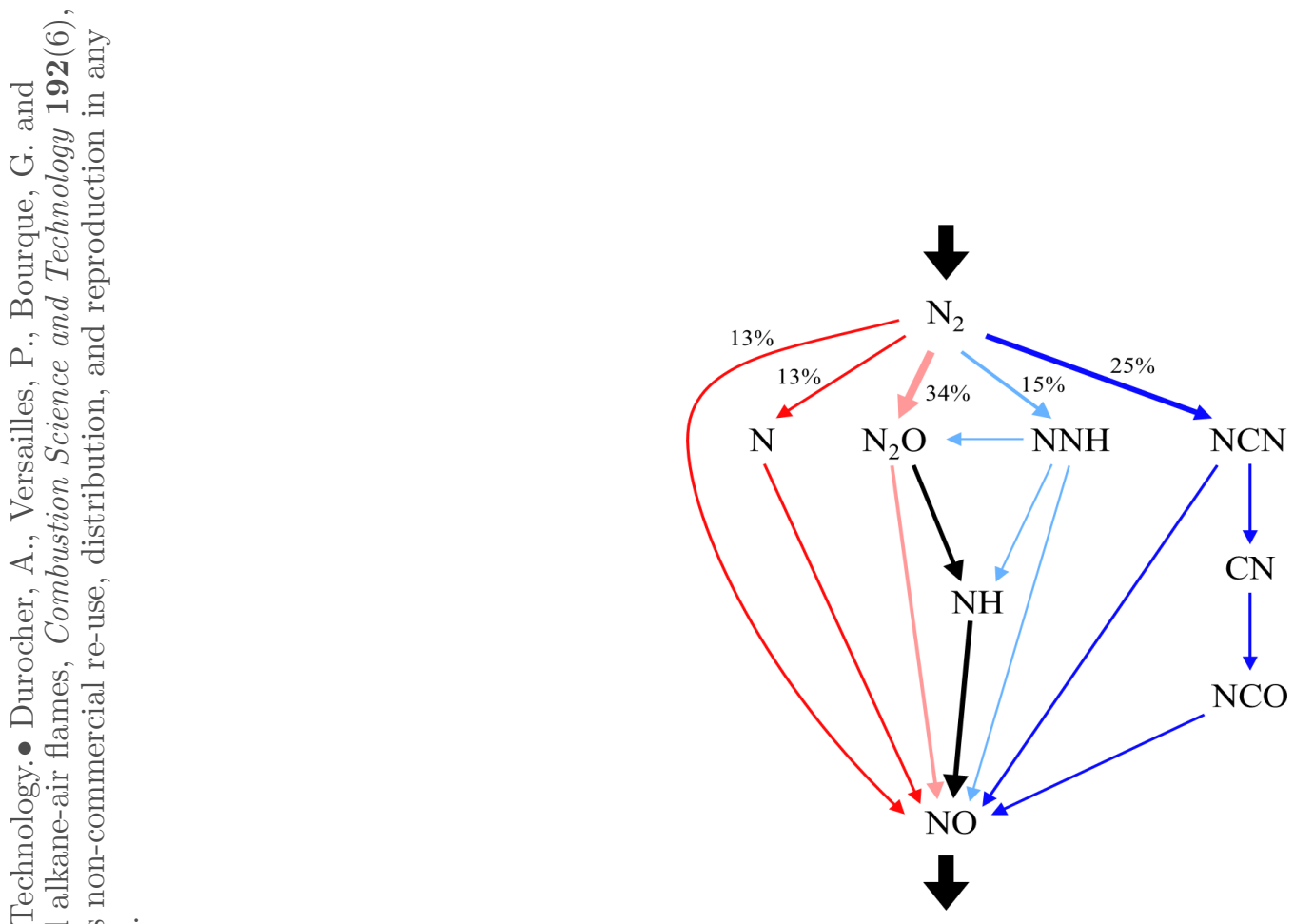

Figure 7: Simplified nitrogen RPA in lean condition. Colours indicate the NO formation routes identified by the branching at the initiation reactions of - thermal, $-\mathrm{N}_{2} \mathrm{O},-\mathrm{NNH}$, and - prompt routes.

methane-air flames. A common set of 29 reactions from the San Diego mechanism is obtained, where the $\mathrm{H}+\mathrm{NCN} \rightleftharpoons \mathrm{HCN}+\mathrm{N}$ reaction is inexistent in San Diego chemistry, since the prompt reaction initiates directly to $\mathrm{HCN}$ through the spin-forbidden reaction. The prompt initiation reactions are included in both mechanism, with their respective uncertainty limits, as part of the common set, even though they follow different reactions. The uncertainty on the spin-forbidden prompt-initiation reaction is considered to capture the contribution of the initiation reaction in both evaluations and allow for comparison between the two models. It can be assimilated to a structural uncertainty in the NO chemistry, present at the time of the mechanism development, that has now been rejected. The importance of the uncertain reactions involved in the $\mathrm{CH}$ pathway to $\mathrm{NO}$ formation through the prompt route is confirmed by the fact that 8 of the 9 reactions from the previous $[\mathrm{CH}]_{\text {peak }}$ analysis are also part of the current set of 30 uncertain and important reactions.

The analysis is performed with $\ell_{2}$ sparse grids, requiring 1,921 quadrature points to develop the 30-variable surrogate model. All solutions are shown in a temporal reference 
frame, with the origin $\left(\tau=0\right.$ s) defined at the $[\mathrm{CH}]_{\text {peak }}$ location. This transformation is essential to systematically compare profiles since the flame position, in the stagnation flow, varies with each realization, as shown previously in Fig. 4.

Probability distributions of NO profiles obtained with the two thermochemical models (Fig. 8) are first compared to experimental NO-LIF measurements in atmospheric, jet-wall stagnation flames (Watson et al., 2016, 2017). Following the methodology of Watson and co-workers, the reported LIF intensities are transformed into mole fractions using LIFSim (Bessler et al., 2003) and the latest high-temperature mechanism assembled by the National University of Ireland, Galway (NUIG), with the base chemistry from Aramco 2.0 (Zhou et al., 2016) and the nitrogen chemistry discussed by Zhang et al. (2017).

As expected from the selected reactions, the uncertainty in predictions increases with the number of uncertain reactions, reaching uncertainty intervals spanning up to 500-600\%, consistent with the previous definition of the upper $2 \sigma$ limits over the nominal predictions. Compared to experimental NO-LIF uncertainty of $\pm 20 \%$, the difference in uncertainty magnitudes further highlights the need for a comprehensive approach to constrain uncertainty in kinetic model parameters via targeted experiments along with optimization and inference techniques. The addition of more accurate recent rate measurements to the existing literature should also decrease prediction uncertainties as the smaller prior uncertainties in kinetic parameters would result in thinner propagated distributions. With current mechanisms, however, it is reasonable to say that prediction intervals cover 10-50 ppm to 0-300 ppm for lean to rich conditions, respectively.

Propagation through the NOMecha 2.0 model shows slightly narrower $\pm 2 \sigma$ bands. The two different mechanism structures still exhibit similar $\pm 1 \sigma$ intervals, suggesting that conclusions regarding the uncertainty of a given model are generalizable, up to a certain extent, to other models containing the same set of constituent reactions. Both evaluations show good agreement of the nominal mechanisms with experimental measurements, and the most-probable interval generally captures well the experimental profiles. 

targets such as ignition delay time and flame speed, it is expected that fewer or no infeasible parameter combination will remain, and the predicted uncertainty interval of the quantity of interest will decrease. With the current prior distributions, the remaining cases produce a probability distribution with a sharp low concentrations peak and a wide tail extending into the hundreds of ppm. The highly skewed distribution shape follows the ones obtained in Section 3, where only a subset of reactions that were both $\mathrm{CH}$-sensitive and uncertain were included. Since the prompt pathway dominates in rich flames, the $\mathrm{CH}$ uncertainty is propagated through the prompt-initiation reaction to yield wider distributions than those observed in lean or stoichiometric flames, where other routes dominate the total NO production. This particular distribution shape suggests that, in order to improve predictions of prompt $\mathrm{NO}$, the uncertainty of reactions involved in $\mathrm{CH}$ production and consumption must first be reduced.

\subsection{NO Pathway Analysis}

In the subsequent analysis, the kinetic structure of $\mathrm{NO}_{x}$ submodels without hydrodynamic stretch effects is studied in adiabatic freely-propagating methane-air flames. Concentrations are extracted $10 \mathrm{~ms}$ downstream of the flame to obtain residence times comparable to conventional combustion devices for power generation. The investigation is performed with the NOMecha 2.0 nitrogen chemistry only, using the same 30 most NO-sensitive reactions.

Uncertainties in total $[\mathrm{NO}]$ for flames with $\phi=[0.7-1.3]$ are shown in Fig. 9a. To illustrate the contribution of the four NO pathways to total predictions, vertical slices are taken at $\phi=[0.7,1.0,1.3]$ (Figs. 9b-d), where the envelope of the stacked distributions match the shaded region in Fig. 9a. Using a reaction pathway analysis for each of the collocation points, surrogate models identifying relative individual contributions are constructed using the $\ell_{2}$ sparse grid and are then sampled in Figs. 9b-d. The probability density functions have been normalized to unity to facilitate the comparison between the distribution shapes at different equivalence ratios. 
probable $[\mathrm{NO}$ ] observed at $\sim 140 \mathrm{ppm}$, a slow, almost linear, decrease in probability is observed on the high side. For the current analysis, the uncertainty limits of R1 were increased from the Baulch (2005) preferred limits to match findings from Watson et al. (2016) and Abian et al. (2015). Both studies recommended a specific reaction rate constant below the preferred limit to reconcile model predictions with measurements in stagnation flames and flow reactors, respectively.

At rich conditions (Fig. 9d), the prompt route dominates the production of NO and can be considered the main contributor to uncertainties. The distribution shape resembles the one obtained for $\mathrm{CH}$ concentrations (Fig. 6), exhibiting a more pronounced peak once the uncertainty from additional reactions in the nitrogen chemistry is included. Again, a sharp probability distribution is obtained near $0 \mathrm{ppm}$, while an exponential decay in probability is observed at high concentration values. The $\sim 600 \%$ uncertainty limits obtained with the 30 reactions considered corresponds to a $50 \%$ increase in predictions uncertainty limits by augmenting by a factor of 3 the number of reactions from the previous $9 \mathrm{CH}$-sensitive and uncertain reaction. With 8 reactions of the 30 found in the $[\mathrm{CH}]$ uncertainty analysis, this result implies that accurate prompt-NO modelling requires an accurate and precise description of $\mathrm{CH}$ formation.

\section{Conclusion}

It is known that thermochemical mechanisms are inherently uncertain, and that emissions predictions performed with any of them must currently be validated with experimental measurements or engine testing. The current paper investigates different spectral methods to develop economic and accurate surrogate models to quantify the effect of parametric uncertainties on $\mathrm{NO}_{x}$ emissions predictions.

Using only nine $\mathrm{CH}$-sensitive and uncertain reactions, five polynomial expansions are compared against stochastic flame simulations to verify their capability to capture sharp, complex, probability distributions. In the fast, methylidyne $(\mathrm{CH})$, radical species, perform- 
ing the analysis in the logarithmic space resulted in accurate predictions for every spectral method, suggesting that low-order approaches are sufficient to perform uncertainty quantification and optimization. For $\left[\mathrm{NO}_{x}\right]$ and reference flame speed, every method equally captured the average of the distributions; however, low-order total-order expansions exhibit significant differences in probability distribution shapes, even with an increased number of collocation points. Generally, these approaches overpredict distribution tails.

Sparse grids, using subsets of full tensor-product expansions, are identified as the optimal method to develop accurate surrogate models at low computational costs to quantify uncertainties in emissions due to the local high-order polynomials used in the expansion. They are recommended for future uncertainty quantification and model optimization efforts. For rapid estimation on a daily basis, however, first-order total-order expansion should definitely be used to, at least, provide uncertainty bands along with nominal model predictions.

The propagation of kinetic uncertainties, for nine $\mathrm{CH}$-sensitive and uncertain reactions in the San Diego base chemistry mechanism, resulted in predictions varying up to $+400 \%$ of nominal values. With a common set of 30 NO-sensitive and uncertain reactions, and using two different nitrogen chemistry models, NOMecha 2.0 and San Diego 2004-v2, [NO] prediction intervals increase up to $+600 \%$. In comparison, the experimental uncertainties of $\pm 20-40 \%$ highlight the need for a comprehensive approach, using measurements with inference techniques, to reduce prediction intervals and develop predictive models. The similar intervals obtained with structurally different nitrogen chemistries suggest that estimates of the model uncertainty band are, to a certain extent, generalizable to other mechanisms.

Reaction pathway analyses, performed in this uncertain framework, provide probable contribution intervals for the four NO formation routes. At stoichiometric conditions, the thermal route is dominant and the initiation reaction is found to be responsible for the asymmetrical NO concentration distribution shape, hinting towards lower kinetic rate values to reconcile predictions with measurements. In rich conditions, the prompt route dominates total emissions and exhibits similar distribution shapes as in $[\mathrm{CH}]_{\text {peak }}$, confirming that an 


\begin{abstract}
accurate description of $\mathrm{CH}$ formation is crucial to capture prompt-NO formation.
Current model uncertainties demonstrate the need for a comprehensive approach, using inference techniques, to develop future predictive models. Inherent parametric uncertainties must be acknowledged and constrained before reliable sub-10 ppm predictions can be made with any confidence to design the next generation of low- $\mathrm{NO}_{x}$ engines.
\end{abstract}




\section{Appendix A: Uncertainty-weighted NO-sensitivity analysis}

The identification of the 30 important reactions is first performed with the NOMecha 2.0 nitrogen chemistry (Lamoureux et al., 2016) attached to the base chemistry of the 2016 San Diego mechanism (University of California at San Diego, 2016). The sensitivity of the $[\mathrm{NO}]$ to the reaction rates is obtained in atmospheric-pressure freely propagating flames $5 \mathrm{~ms}$ downstream of the flame for lean, $\phi=0.7$, stoichiometric, $\phi=1.0$, and rich, $\phi=$ 1.3, methane-air flames to identify reactions that contribute to emissions predictions in a variety of conditions. Uncertainty factors extracted from the literature (Baulch, 2005; Baulch et al., 1992; Tsang and Hampson, 1986) are then applied to the logarithmic sensitivity to identify reactions that greatly affect NO formation. Additionally, the uncertainty factor of the thermal initiation reaction R1 is consistent with that used by Watson et al. (2016), where the lower limit was reduced to reconcile model predictions with experimental measurements.

The results of the uncertainty-weighted NO-sensitivity analysis are shown in Fig. 10, where absolute logarithmic sensitivities are shown on the left, and absolute logarithmic sensitivities multiplied by the uncertainty factor are shown on the right. Reactions are ordered by sensitivity to highlight the contribution to uncertainty from reactions that are less sensitive, but more uncertain, to the analysis. For the current work, 30 reactions, shown in bold in Fig. 10, present a contribution to the uncertain sensitivity above 0.1 and are identified as the set of important reactions to NO formation used to quantify the impact of kinetic uncertainties in $[\mathrm{NO}]$.

Table A1 lists the nominal reactions identified for the NOMecha 2.0 mechanism, where the reaction rate parameters $A, n$, and $E_{a}$ have units of (cm, mole, s), (-), and (cal, mole), respectively. As presented in the current work, asymmetric uncertainty limits are defined to retain the optimized mechanism structure while satisfying the preferred uncertainty limits.

Similarly, the procedure is performed for the 2004 San Diego nitrogen chemistry. Results of the uncertainty-weighted NO-sensitivity analysis are shown in Fig. 11, following the same labelling. In this case, 31 reactions are identified above the threshold, defined previously, 
to be considered as important in the current analysis. To systematically compare predicted uncertainties between models, however, a common set of reactions is derived from the more recent NOMecha 2.0 chemistry to study the contribution of the four formation pathways to total emissions. Among the 30 reactions identified, 23 are found in the base chemistry, which is shared by both assembled mechanisms; 6 show unique rate parameters found in their respective nitrogen chemistry; and 1 is non-existent in the San Diego chemistry since this model initiates the prompt-NO route directly to HCN.

The 6 different reactions, found in the San Diego nitrogen chemistry, are shown in Tab. A2 with their respective rate parameters and uncertainty factors. The remaining reactions used in the uncertainty analysis are common to both mechanisms and can be found in Tab. A1. 
Uncertainty-weighted sensitivity analysis

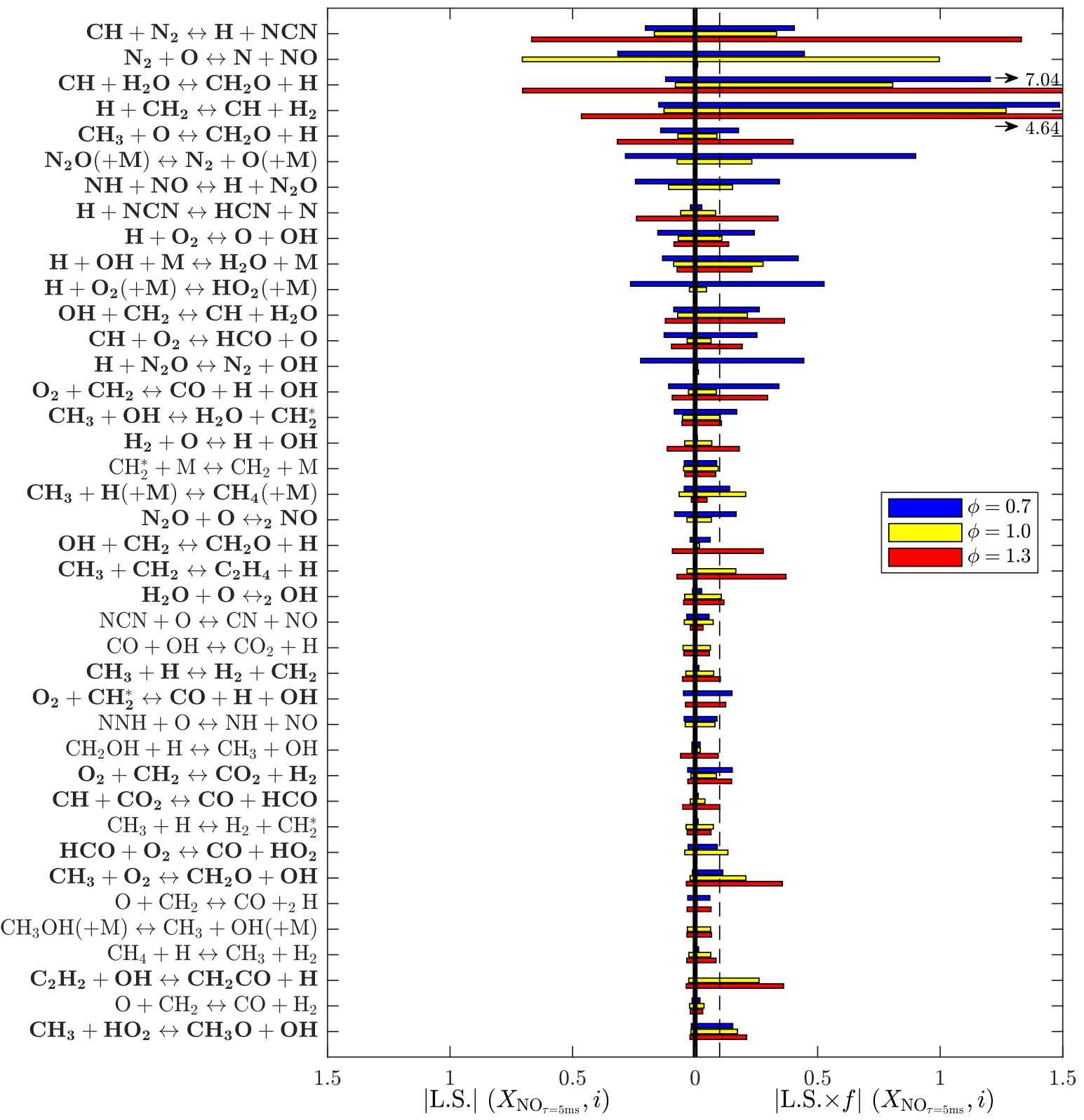

Figure 10: Analysis performed with NOMecha 2.0 attached to the San Diego base chemistry. Left: absolute logarithmic sensitivity for the targeted NO species. Right: sensitivities are multiplied by the uncertainty factor $f$. Bold reactions are used in the uncertainty analysis. 
Uncertainty-weighted sensitivity analysis

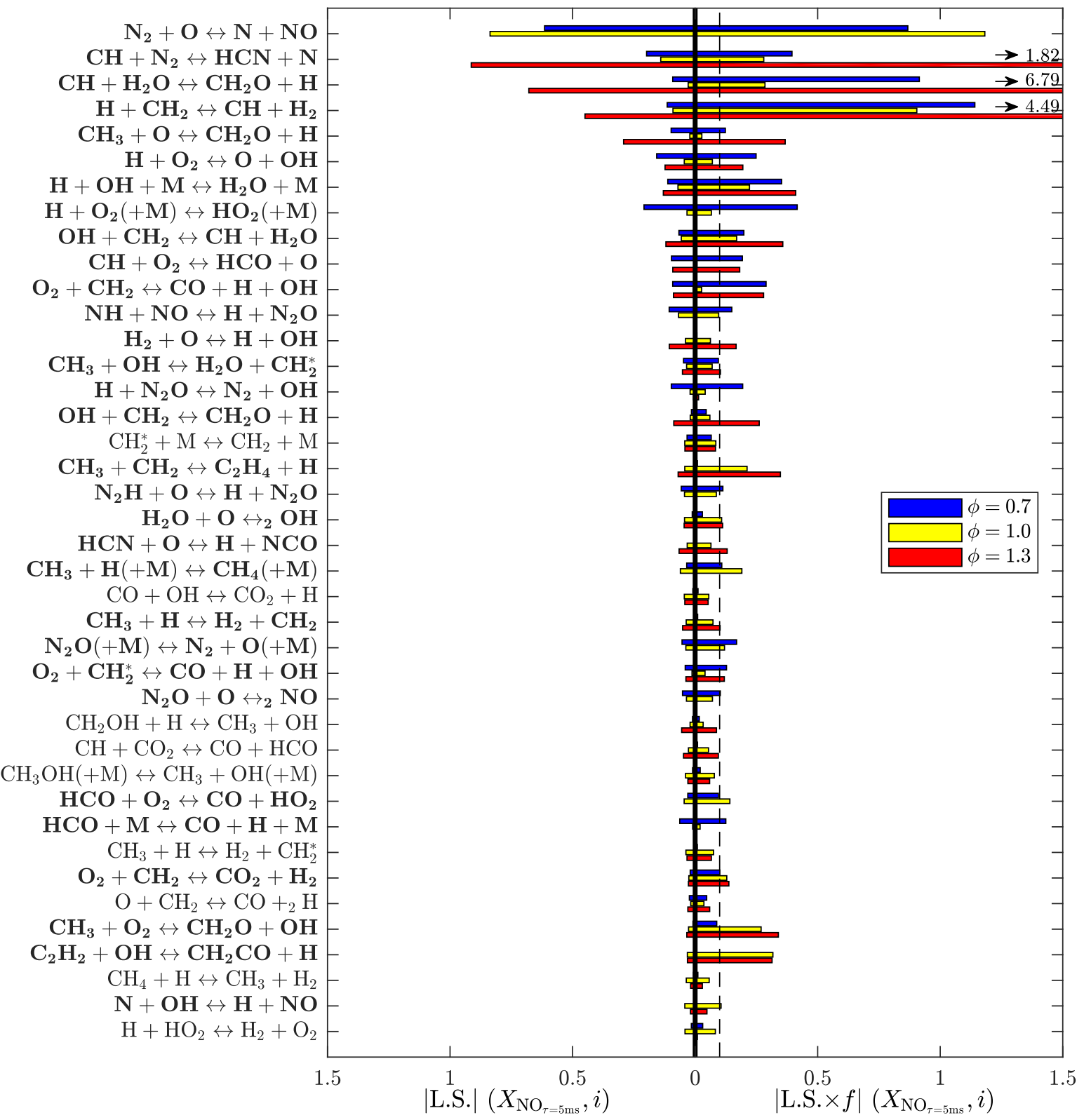

Figure 11: Analysis performed with the 2004-v2 nitrogen chemistry from the San Diego mechanism attached to 2016 base chemistry(University of California at San Diego, 2016). Same legend as Fig. 10. 
Table A1: Nominal Reaction Rate Parameters and Uncertainty Bounds for NOMecha 2.0, $1 / f_{i, \text { low }}$ and $f_{i, \text { high }}$ for the 30 most NO-sensitive Reactions.

\begin{tabular}{|c|c|c|c|c|c|c|c|c|}
\hline & \multicolumn{2}{|l|}{ Reactions } & $\begin{array}{c}A \\
{[\mathrm{~cm}, \mathrm{~mol}, \mathrm{~s}]}\end{array}$ & $n$ & $\begin{array}{c}E_{\mathrm{a}} \\
{[\mathrm{cal}, \mathrm{mol}]}\end{array}$ & $1 / f_{i, \text { low }}$ & \multicolumn{2}{|l|}{$f_{i, \text { high }}$} \\
\hline 1 & $\mathrm{CH}+\mathrm{N}_{2} \rightleftharpoons \mathrm{H}+\mathrm{NCN}$ & & $1.95 \mathrm{E} 12$ & 0.000 & 16,915 & 0.0298 & 1.406 & \\
\hline 2 & $\mathrm{~N}_{2}+\mathrm{O} \rightleftharpoons \mathrm{N}+\mathrm{NO}$ & & $1.00 \mathrm{E} 14$ & 0.000 & 75,490 & 0.5000 & 2.164 & \\
\hline 3 & $\mathrm{CH}+\mathrm{H}_{2} \mathrm{O} \rightleftharpoons \mathrm{CH}_{2} \mathrm{O}+\mathrm{H}$ & & $4.15 \mathrm{E} 15$ & -0.750 & 0 & 0.0110 & 1.067 & \\
\hline 4 & $\mathrm{H}+\mathrm{CH}_{2} \rightleftharpoons \mathrm{CH}+\mathrm{H}_{2}$ & & $1.93 \mathrm{E} 13$ & 0.000 & -1787.76 & 0.5883 & 32.399 & \\
\hline 5 & $\mathrm{CH}_{3}+\mathrm{O} \rightleftharpoons \mathrm{CH}_{2} \mathrm{O}+\mathrm{H}$ & & 8.43E13 & 0.000 & 0 & 0.7944 & 1.259 & \\
\hline \multirow[t]{2}{*}{6} & $\mathrm{~N}_{2} \mathrm{O}(+\mathrm{M}) \rightleftharpoons \mathrm{N}_{2}+\mathrm{O}(+\mathrm{M})$ & $k_{\infty}$ & $1.30 \mathrm{E} 12$ & 0.000 & $62,570.0$ & 0.3070 & 1.559 & \\
\hline & & $k_{0}$ & $4.00 \mathrm{E} 14$ & 0.000 & $56,600.0$ & & & \\
\hline 7 & $\mathrm{NH}+\mathrm{NO} \rightleftharpoons \mathrm{H}+\mathrm{N}_{2} \mathrm{O}$ & & $1.75 \mathrm{E} 14$ & -0.351 & -244 & 0.4475 & 1.354 & \\
\hline 8 & $\mathrm{H}+\mathrm{NCN} \rightleftharpoons \mathrm{HCN}+\mathrm{N}$ & & 3.84E14 & 0.000 & 7956 & 0.6426 & 1.283 & $a$ \\
\hline 9 & $\mathrm{H}+\mathrm{O}_{2} \rightleftharpoons \mathrm{O}+\mathrm{OH}$ & & $3.52 \mathrm{E} 16$ & -0.700 & $17,069.79$ & 0.6814 & 1.496 & \\
\hline 10 & $\mathrm{H}+\mathrm{OH}+\mathrm{M} \rightleftharpoons \mathrm{H}_{2} \mathrm{O}+\mathrm{M}$ & & $4.00 \mathrm{E} 22$ & -2.000 & 0 & 0.1749 & 1.749 & \\
\hline \multirow[t]{3}{*}{11} & $\mathrm{H}+\mathrm{O}_{2}(+\mathrm{M}) \rightleftharpoons \mathrm{HO}_{2}(+\mathrm{M})$ & $k_{\infty}$ & $4.65 \mathrm{E} 12$ & 0.440 & 0.0 & 0.5113 & 2.118 & \\
\hline & & $k_{0}$ & $5.75 \mathrm{E} 19$ & -1.400 & 0.0 & & & \\
\hline & & Troe & \multicolumn{6}{|c|}{$A=0.5, T_{3}=1 \mathrm{E}-30, T_{1}=1 \mathrm{E} 30$} \\
\hline 12 & $\mathrm{OH}+\mathrm{CH}_{2} \rightleftharpoons \mathrm{CH}+\mathrm{H}_{2} \mathrm{O}$ & & $9.63 \mathrm{E} 06$ & 2.000 & 2999.52 & 0.0410 & 1.944 & $b$ \\
\hline 13 & $\mathrm{CH}+\mathrm{O}_{2} \rightleftharpoons \mathrm{HCO}+\mathrm{O}$ & & 8.40E10 & 0.760 & -478.01 & 0.4197 & 5.157 & \\
\hline 14 & $\mathrm{H}+\mathrm{N}_{2} \mathrm{O} \rightleftharpoons \mathrm{N}_{2}+\mathrm{OH}$ & & $3.30 \mathrm{E} 10$ & 0.000 & 4729 & 0.4565 & 3.462 & \\
\hline 15 & $\mathrm{O}_{2}+\mathrm{CH}_{2} \rightleftharpoons \mathrm{CO}+\mathrm{H}+\mathrm{OH}$ & & $5.58 \mathrm{E} 12$ & 0.000 & 1491.4 & 1.0000 & 13.814 & ${ }^{c}$ \\
\hline 16 & $\mathrm{CH}_{3}+\mathrm{OH} \rightleftharpoons \mathrm{H}_{2} \mathrm{O}+\mathrm{CH}_{2}^{*}$ & & $2.36 \mathrm{E} 17$ & -1.225 & 1811 & 0.2995 & 1.340 & \\
\hline 17 & $\mathrm{H}_{2}+\mathrm{O} \rightleftharpoons \mathrm{H}+\mathrm{OH}$ & & $5.06 \mathrm{E} 04$ & 2.670 & 6290.63 & 0.3486 & 1.825 & \\
\hline \multirow[t]{3}{*}{18} & $\mathrm{CH}_{3}+\mathrm{H}(+\mathrm{M}) \rightleftharpoons \mathrm{CH}_{4}(+\mathrm{M})$ & $k_{\infty}$ & $9.965 \mathrm{E} 15$ & -0.630 & 382.89 & 0.5244 & 6.173 & \\
\hline & & $k_{0}$ & $1.938 \mathrm{E} 33$ & -4.760 & 2440.01 & & & \\
\hline & & Troe & \multicolumn{6}{|c|}{$A=0.783, T_{3}=74.0, T_{1}=2941, T_{2}=6964$} \\
\hline 19 & $\mathrm{~N}_{2} \mathrm{O}+\mathrm{O} \rightleftharpoons 2 \mathrm{NO}$ & & $9.20 \mathrm{E} 13$ & 0.000 & 27679 & 0.5314 & 1.812 & \\
\hline 20 & $\mathrm{OH}+\mathrm{CH}_{2} \rightleftharpoons \mathrm{CH}_{2} \mathrm{O}+\mathrm{H}$ & & $2.50 \mathrm{E} 13$ & 0.000 & 0 & 0.2410 & 2.167 & $b$ \\
\hline 21 & $\mathrm{CH}_{3}+\mathrm{CH}_{2} \rightleftharpoons \mathrm{C}_{2} \mathrm{H}_{4}+\mathrm{H}$ & & $4.22 \mathrm{E} 13$ & 0.000 & 0 & 0.4052 & 7.238 & \\
\hline 22 & $\mathrm{H}_{2} \mathrm{O}+\mathrm{O} \rightleftharpoons 2 \mathrm{OH}$ & & $7.00 \mathrm{E} 05$ & 2.330 & $14,548.28$ & 0.1715 & 2.466 & $b$ \\
\hline 23 & $\mathrm{CH}_{3}+\mathrm{H} \rightleftharpoons \mathrm{H}_{2}+\mathrm{CH}_{2}$ & & $1.80 \mathrm{E} 14$ & 0.000 & $15,105.16$ & 0.5012 & 1.995 & \\
\hline 24 & $\mathrm{O}_{2}+\mathrm{CH}_{2}^{*} \rightleftharpoons \mathrm{CO}+\mathrm{H}+\mathrm{OH}$ & & $3.13 \mathrm{E} 13$ & 0.000 & 0 & 0.3185 & 3.143 & \\
\hline 25 & $\mathrm{O}_{2}+\mathrm{CH}_{2} \rightleftharpoons \mathrm{CO}_{2}+\mathrm{H}_{2}$ & & $2.23 \mathrm{E} 12$ & 0.000 & 1491.4 & 0.2535 & 6.536 & \\
\hline 26 & $\mathrm{CH}+\mathrm{CO}_{2} \rightleftharpoons \mathrm{CO}+\mathrm{HCO}$ & & $4.80 \mathrm{E} 01$ & 3.220 & -3226.58 & 0.6928 & 4.440 & \\
\hline 27 & $\mathrm{HCO}+\mathrm{O}_{2} \rightleftharpoons \mathrm{CO}+\mathrm{HO}_{2}$ & & $7.58 \mathrm{E} 12$ & 0.000 & 409.89 & 0.2763 & 2.744 & \\
\hline 28 & $\mathrm{CH}_{3}+\mathrm{O}_{2} \rightleftharpoons \mathrm{CH}_{2} \mathrm{O}+\mathrm{OH}$ & & 3.30E11 & 0.000 & 8941.2 & 0.0305 & 7.048 & \\
\hline 29 & $\mathrm{C}_{2} \mathrm{H}_{2}+\mathrm{OH} \rightleftharpoons \mathrm{CH}_{2} \mathrm{CO}+\mathrm{H}$ & & $1.90 \mathrm{E} 07$ & 1.700 & 999.04 & 0.0193 & 2.607 & \\
\hline 30 & $\mathrm{CH}_{3}+\mathrm{HO}_{2} \rightleftharpoons \mathrm{CH}_{3} \mathrm{O}+\mathrm{OH}$ & & $5.00 \mathrm{E} 12$ & 0.000 & 0 & 0.3613 & 36.13 & \\
\hline
\end{tabular}

Nominal uncertainty factors $f_{i}$ are obtained from Baulch (2005) except:

${ }^{a}$ Faßheber et al. (2014)

${ }^{b}$ Tsang and Hampson (1986)

${ }^{c}$ Baulch et al. (1992) 
Table A2: Additional reaction rate parameters and uncertainty bounds, $1 / f_{i, \text { low }}$ and $f_{i \text {, high }}$ for the San Diego nitrogen chemistry.

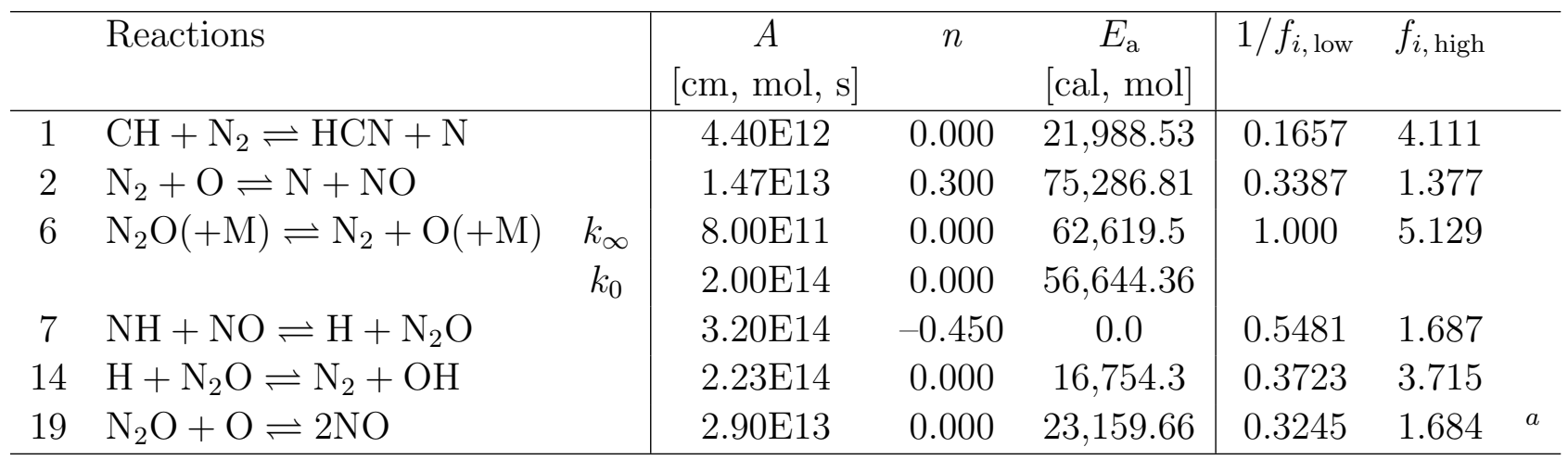

Nominal uncertainty factors $f_{i}$ are obtained from Baulch (2005) except:

${ }^{a}$ Tsang and Hampson (1986) 


\section{References}

Abian, M., Alzueta, M. U. and Glarborg, P. (2015), Formation of NO from $\mathrm{N}_{2} / \mathrm{O}_{2}$ mixtures in a flow reactor: toward an accurate prediction of thermal NO, International Journal of Chemical Kinetics 47(8), 518-532.

doi: 10.1002/kin.20929

Adams, B., Bauman, L., Bohnhoff, W., Dalbey, K., Ebeida, M., Eddy, J., Eldred, M., Hough, P., Hu, K., Jakeman, J., Stephens, J., Swiler, L., Vigil, D. and Wildey, T. (2015), Dakota, A Multilevel Parallel Object-Oriented Framework for Design Optimization, Parameter Estimation, Uncertainty Quantification, and Sensitivity Analysis: Version 6.0 User's Manual, Technical report, Sandia Technical Report SAND2014-4633.

Askey, R. and Wilson, J. (1985), Some Basic Hypergeometric Orthogonal Polynomials that Generalize Jacobi Polynomials, american m edn, American Mathematical Society, Providence.

Baulch, D., Cobos, C., Cox, R., Esser, C., Frank, P., Just, T., Kerr, J., Pilling, M., Troe, J., Walker, R. and Warnatz, J. (1992), Evaluated kinetic data for combustion modelling, Journal of Physical and Chemical Reference Data 21(3), 411-734.

doi: $10.1063 / 1.555908$

Baulch, D. L. (2005), Evaluated Kinetic Data for Combustion Modeling : Supplement II, Journal of Physical and Chemical Reference Data 34(3), 757-1397.

doi: $10.1063 / 1.1748524$

Bessler, W. G., Schulz, C., Sick, V. and Daily, J. W. (2003), A versatile modeling tool for nitric oxide lif spectra, in 'Proceedings of the Third Joint Meeting of the US Sections of The Combustion Institute', p. P105.

Correa, S. M. (1993), A Review of $\mathrm{NO}_{x}$ Formation Under Gas-Turbine Combustion Conditions, Combustion Science and Technology 87(1-6), 329-362.

doi: 10.1080/00102209208947221

Davis, M. J., Liu, W. and Sivaramakrishnan, R. (2017), Global sensitivity analysis with small sample sizes: Ordinary least squares approach, The Journal of Physical Chemistry A 121(3), 553-570.

doi: 10.1021/acs.jpca.6b09310

Faßheber, N., Dammeier, J. and Friedrichs, G. (2014), Direct measurements of the total rate constant of the reaction $\mathrm{NCN}+\mathrm{H}$ and implications for the product branching ratio and the enthalpy of formation of NCN, Physical Chemistry Chemical Physics 16(23), 11647-11657.

Frenklach, M., Wang, H. and Rabinowitz, M. J. (1992), Optimization and analysis of large chemical kinetic mechanisms using the solution mapping method-combustion of methane, Progress in Energy and Combustion Science 18(1), 47-73.

doi: 10.1016/0360-1285(92)90032-V 
Glarborg, P., Miller, J. A., Ruscic, B. and Klippenstein, S. J. (2018), Modeling nitrogen chemistry in combustion, Progress in Energy and Combustion Science 67, 31-68. doi: $10.1016 /$ j.pecs.2018.01.002

Göke, S., Schimek, S., Terhaar, S., Reichel, T., Göckeler, K., Krüger, O., Fleck, J., Griebel, P. and Paschereit, C. O. (2014), Influence of Pressure and Steam Dilution on $\mathrm{NO}_{x}$ and CO Emissions in a Premixed Natural Gas Flame, Journal of Engineering for Gas Turbines and Power 136(9), 091508.

doi: $10.1115 / 1.4026942$

Goodwin, D., Moffat, H. and Speth, R. (2016), 'Cantera: An object-oriented software toolkit for chemical kinetics, thermodynamics, and transport processes', http://www.cantera.org. doi: $10.5281 /$ zenodo.170284

Grcar, J. F., Day, M. S. and Bell, J. B. (2006), A taxonomy of integral reaction path analysis, Combustion Theory and Modelling 10(4), 559-579. doi: 10.1080/13647830600551917

Guo, H., Smallwood, G. J., Liu, F., Ju, Y. and Gülder, Ö. L. (2005), The effect of hydrogen addition on flammability limit and $\mathrm{NO}_{x}$ emission in ultra-lean counterflow $\mathrm{CH}_{4}$ /air premixed flames, Proceedings of the Combustion Institute 30(1), 303-311.

doi: $10.1016 /$ j.proci.2004.08.177

Lamoureux, N., El Merhubi, H., Pillier, L., de Persis, S. and Desgroux, P. (2016), Modeling of NO formation in low pressure premixed flames, Combustion and Flame 163, 557-575. doi: 10.1016/j.combustflame.2015.11.007

Lieuwen, T., Chang, M. and Amato, A. (2013), Stationary gas turbine combustion: Technology needs and policy considerations, Combustion and Flame 160(8), 1311-1314.

doi: $10.1016 /$ j.combustflame.2013.05.001

Lipardi, A. C., Versailles, P., Watson, G. M., Bourque, G. and Bergthorson, J. M. (2017), Experimental and numerical study on $\mathrm{NO}_{x}$ formation in $\mathrm{CH}_{4^{-}}$-air mixtures diluted with exhaust gas components, Combustion and Flame 179, 325-337.

doi: 10.1016/j.combustflame.2017.02.009

Miller, J. A. and Bowman, C. T. (1989), Mechanism and Modeling of Nitrogen Chemistry in Combustion, Progress in Energy and Combustion Science 15(4), 287-338.

doi: 10.1016/0360-1285(89)90017-8

Moskaleva, L. and Lin, M. (2000), The spin-conserved reaction $\mathrm{CH}+\mathrm{N}_{2} \rightarrow \mathrm{H}+\mathrm{NCN}$ : $\mathrm{A}$ major pathway to prompt NO studied by quantum/statistical theory calculations and kinetic modeling of rate constant, Proceedings of the Combustion Institute 28(2), 23932401.

doi: 10.1016/S0082-0784(00)80652-9

Prager, J., Najm, H. N., Sargsyan, K., Safta, C. and Pitz, W. J. (2013), Uncertainty quantification of reaction mechanisms accounting for correlations introduced by rate rules and 
fitted Arrhenius parameters, Combustion and Flame 160(9), 1583-1593.

doi: 10.1016/j.combustflame.2013.01.008

Reagan, M. T., Najm, H., Pebay, P., Knio, O. and Ghanem, R. (2005), Quantifying uncertainty in chemical systems modeling, International journal of chemical kinetics 37(6), 368382.

doi: $10.1002 /$ kin.20081

Røkke, P. E., Hustad, J. E., Røkke, N. A. and Svendsgaard, O. B. (2003), Technology update on gas turbine dual fuel, dry low emission combustion systems, in 'Proceedings of ASME Turbo Expo', American Society of Mechanical Engineers, pp. GT2003-38112. doi: $10.1115 /$ GT2003-38112

Schofield, K. (2012), Large Scale Chemical Kinetic Models of Fossil Fuel Combustion: Adequate as Engineering Models - No More, No Less, Energy \&f Fuels 26(9), 5468-5480. doi: $10.1021 /$ ef300858s

Sheen, D. A. and Wang, H. (2011), The method of uncertainty quantification and minimization using polynomial chaos expansions, Combustion and Flame 158(12), 2358-2374. doi: 10.1016/j.combustflame.2011.05.010

Slavinskaya, N. A., Abbasi, M., Starcke, J. H., Whitside, R., Mirzayeva, A., Riedel, U., Li, W., Oreluk, J., Hegde, A., Packard, A., Frenklach, M., Gerasimov, G. and Shatalov, O. (2017), Development of an uncertainty quantification predictive chemical reaction model for syngas combustion, Energy \& Fuels 31(3), 2274-2297.

doi: 10.1021/acs.energyfuels.6b02319

Smith, G. P., Golden, D. M., Frenklach, M., Moriarty, N. W., Eiteneer, B., Goldenberg, M., Bowman, C. T., Hanson, R. K., Song, S., Gardiner, W. C. J., Lissianski, V. V. and Qin, Z. (1999), 'GRI-Mech 3.0', http://www.me.berkeley.edu/gri_mech/.

Smith, R. C. (2013), Uncertainty Quantification: Theory, Implementation, and Applications, Computational Science and Engineering, SIAM, Philadelphia.

Smolyak, S. A. (1963), Quadrature and interpolation formulas for tensor products of certain classes of functions, in 'Doklady Akademii Nauk', Vol. 148, Russian Academy of Sciences, pp. 1042-1045.

Tomlin, A. S. (2006), The use of global uncertainty methods for the evaluation of combustion mechanisms, Reliability Engineering 65 System Safety 91, 1219-1231.

doi: 10.1016/j.ress.2005.11.026

Tsang, W. and Hampson, R. F. (1986), Chemical Kinetic Data Base for Combustion Chemistry. Part I. Methane and Related Compounds, Journal of Physical and Chemical Reference Data 15(3), 1087-1279.

doi: 10.1063/1.555759 
Turányi, T. and Tomlin, A. S. (2016), Analysis of Kinetic Reaction Mechanisms, Springer, Berlin. doi: $10.1007 / 978-3-662-44562-4$

University of California at San Diego (2005), 'Chemical-kinetic mechanisms for combustion applications', http://combustion.ucsd.edu. San Diego Mechanism web page, Mechanical and Aerospace Engineering (Combustion Research).

University of California at San Diego (2016), 'Chemical-kinetic mechanisms for combustion applications', http://combustion.ucsd.edu. San Diego Mechanism web page, Mechanical and Aerospace Engineering (Combustion Research).

Versailles, P. $\left(2017^{a}\right)$, $\mathrm{CH}$ formation in premixed flames of $\mathrm{C}_{1}-\mathrm{C}_{4}$ alkanes: assessment of current chemical modelling capability against experiments, PhD thesis, McGill University.

Versailles, P., Durocher, A., Bourque, G. and Bergthorson, J. M. (2018), Nitric oxide formation in lean, methane-air stagnation flames at supra-atmospheric pressures, Proceedings of the Combustion Institute .

doi: $10.1016 /$ j.proci.2018.05.060

Versailles, P., Watson, G. M. G., Durocher, A., Bourque, G. and Bergthorson, J. M. (2017 $)$, Thermochemical mechanism optimization for accurate predictions of $\mathrm{CH}$ concentrations in premixed flames of $\mathrm{C}_{1}-\mathrm{C}_{3}$ alkane fuels, Journal of Engineering for Gas Turbines and Power .

doi: $10.1115 / 1.4038416$

Versailles, P., Watson, G. M. G., Lipardi, A. C. A. and Bergthorson, J. M. (2016), Quantitative $\mathrm{CH}$ measurements in atmospheric-pressure, premixed flames of $\mathrm{C}_{1}-\mathrm{C}_{4}$ alkanes, Combustion and Flame 165, 109-124.

doi: 10.1016/j.combustflame.2015.11.001

Wang, H. and Sheen, D. A. (2015), Combustion kinetic model uncertainty quantification, propagation and minimization, Progress in Energy and Combustion Science 47, 1-31.

doi: $10.1016 /$ j.pecs.2014.10.002

Watson, G. M. G., Versailles, P. and Bergthorson, J. M. (2016), NO formation in premixed flames of $\mathrm{C}_{1}-\mathrm{C}_{3}$ alkanes and alcohols, Combustion and Flame 169, 242-260. doi: 10.1016/j.combustflame.2016.04.015

Watson, G. M. G., Versailles, P. and Bergthorson, J. M. (2017), NO formation in rich premixed flames of $\mathrm{C}_{1}-\mathrm{C}_{4}$ alkanes and alcohols, Proceedings of the Combustion Institute 36(1), 627-635.

doi: $10.1016 /$ j.proci.2016.06.108

Wiener, N. (1938), The Homogeneous Chaos, American Journal of Mathematics 60(4), 897936.

doi: $10.2307 / 2371268$ 
Winokur, J., Kim, D., Bisetti, F., Le Maître, O. P. and Knio, O. M. (2016), Sparse pseudo spectral projection methods with directional adaptation for uncertainty quantification, Journal of Scientific Computing 68(2), 596-623.

Xiu, D. (2010), Numerical methods for stochastic computations: A spectral method approach, Princeton university press, Princeton.

Zádor, J., Zsély, I. G., Turányi, T., Ratto, M., Tarantola, S. and Saltelli, A. (2005), Local and global uncertainty analyses of a methane flame model, The Journal of Physical Chemistry A 109(43), 9795-9807. doi: $10.1021 /$ jp053270i

Zhang, Y., Mathieu, O., Petersen, E. L., Bourque, G. and Curran, H. J. (2017), Assessing the predictions of a $\mathrm{NO}_{x}$ kinetic mechanism on recent hydrogen and syngas experimental data, Combustion and Flame 182, 122-141. doi: 10.1016/j.combustflame.2017.03.019

Zhou, C.-W., Li, Y., O’Connor, E., Somers, K. P., Thion, S., Keesee, C., Mathieu, O., Petersen, E. L., DeVerter, T. A., Oehlschlaeger, M. A. et al. (2016), A comprehensive experimental and modeling study of isobutene oxidation, Combustion and Flame 167, 353379.

doi: 10.1016/j.combustflame.2016.01.021

Zsély, I. G., Zádor, J. and Turányi, T. (2008), Uncertainty analysis of NO production during methane combustion, Int. J. Chem. Kinet. 40(11), 754-768.

doi: $10.1002 /$ kin.20373 